\title{
Is the Intrinsic Value of Macroeconomic News Announcements Related to their Asset Price Impact?*
}

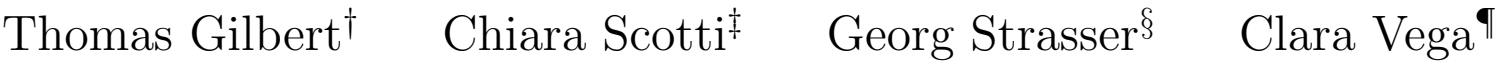

April 23, 2015

\begin{abstract}
The literature documents a heterogeneous asset price response to macroeconomic news announcements: Some announcements have a strong impact on asset prices and others do not. In order to explain these differences, we estimate a novel measure of the intrinsic value of a macroeconomic announcement, which we define as the announcement's ability to nowcast GDP growth, inflation, and the Federal Funds Target Rate. Using the same nowcasting framework, we then decompose this intrinsic value into the announcement's characteristics: its relation to fundamentals, timing, and revision noise. We find that in the 1998-2013 period, a significant fraction of the variation in the announcements' price impact on the Treasury bond futures market can be explained by differences in intrinsic value. Furthermore, our novel measure of timing explains significantly more of this variation than the announcements' relation to fundamentals, reporting lag (which previous studies have used as a measure of timing), or revision noise.
\end{abstract}

Keywords: Macroeconomic announcements, price discovery, learning, macroeconomic forecasting, coordination role of public information, central bank policy

JEL classification: G14, E44

*For comments and suggestions on an earlier and preliminary draft, we thank Torben Andersen, Tim Bollerslev, Dean Croushore, Eric Ghysels, Michael McCracken, Barbara Rossi, Jonathan Wright, the participants of the $20^{t h}(\mathrm{EC})^{2}$ Conference, the $6^{\text {th }}$ ECB Workshop on Forecasting Techniques, the Applied Econometrics and Forecasting in Macroeconomics and Finance Workshop at the St. Louis Fed, the Conference on Real-Time Data Analysis, Methods and Applications at Federal Reserve Bank of Philadelphia, the Conference on Computing in Economics and Finance, the $2^{\text {nd }}$ Humboldt-Copenhagen Conference on Financial Econometrics, and the seminar participants at the University of Nürnberg and the Ifo Institute. We thank Domenico Giannone, Lucrezia Reichlin, and David Small for sharing their computer code with us, and Margaret Walton for outstanding research assistance. The views expressed are those of the individual authors and do not necessarily reflect official positions of the Federal Reserve System, or the Board of Governors.

${ }^{\dagger}$ Foster School of Business, Department of Finance, University of Washington (gilbertt@u.washington.edu)

${ }^{\ddagger}$ Board of Governors, Federal Reserve System, Washington D.C. (chiara.scotti@frb.gov)

${ }^{\S}$ Department of Economics, Boston College (georg.strasser@bc.edu)

`Board of Governors, Federal Reserve System, Washington D.C. (clara.vega@frb.gov) 


\section{Introduction}

An extensive literature has linked macroeconomic news announcements to movements in stock, government bond, and foreign exchange returns ${ }^{1}$ Some of these studies have highlighted the heterogeneous response of asset prices to news: A few announcements have a strong impact on asset prices, but most do not. However, there are surprisingly few studies that investigate what causes this heterogeneous response. In this paper, we help fill in the void by (i) proposing and estimating novel empirical measures of announcements' intrinsic value, and (ii) relating differences in the asset price responses to differences in our novel measures.

Motivated by economic theory, we define and estimate the intrinsic value of an announcement as its importance in nowcasting the following primitives or fundamentals: the U.S. Gross Domestic Product (GDP), the GDP Price Deflator, and the Federal Funds Target Rate (FFTR). More precisely, intrinsic value is the nowcasting weight placed on the macroeconomic announcement at the time of its release. We focus on understanding the U.S. Treasury bond market's response to macroeconomic news announcements, and thus our choice of primitives is consistent with this literature. In particular, Beechey and Wright (2009), who study the bond market response to macroeconomic news, group announcements into three broad categories: news about prices, news about real output, and news about monetary policy. ${ }^{2}$ The primitives we choose are representative of each of these broad categories.

\footnotetext{
${ }^{1}$ The literature is vast and we make no attempt to survey it. Most studies analyze the response of each asset class in isolation. Many authors have studied the government bond market response to macroeconomic announcements, including Fleming and Remolona (1997, 1999), Balduzzi, Elton, and Green (2001), Goldberg and Leonard (2003), Gürkaynak, Sack, and Swanson (2005), and Beechey and Wright (2009). Others have studied the foreign exchange market response, including Almeida, Goodhart, and Payne (1998), Andersen, Bollerslev, Diebold, and Vega (2003), and Ehrmann and Fratzscher (2005). See Neely and Dey (2010) for an excellent review of the literature on foreign exchange response to macroeconomic announcements. Others have studied the stock market response, including Flannery and Protopapadakis (2002), Ehrmann and Fratzscher (2004), Bernanke and Kuttner (2005), and Bekaert and Engstrom (2010). And others have studied multiple asset classes simultaneously, including Boyd, Hu, and Jagannathan (2005), Faust, Rogers, Wang, and Wright (2007) and Bartolini, Goldberg, and Sacarny (2008).

${ }^{2}$ Nominal Treasury bond prices embody inflation expectations and expected future real interest rates; therefore, news about prices, real output, and monetary policy appear to be natural choices of primitives for sovereign bond prices. However, when studying the response of another asset class to macroeconomic announcements, researchers should consider other primitives. For example, when analyzing the impact of
} 
Next, we decompose this intrinsic value into announcement's characteristics that capture its timing, revision noise, and relation to fundamentals using the same nowcasting framework. While the previous literature has discussed each of the first two characteristics in isolation, our contribution is to formally define all three announcement characteristics coherently within a single nowcasting framework. We define the tardiness of a macroeconomic announcement as the percent loss in the nowcasting weight due to the delay in its release relative to the most timely announcement. Similarly, we define revision noise as the percent loss in its nowcasting weight due to the announcement's future revisions. Our definition of the announcement's relation to fundamentals is its importance in nowcasting our three primitives independent of the announcement's revisions and release time.

Finally, we relate an announcement's intrinsic value, tardiness, revision noise, and relation to fundamentals to the announcement's asset price impact. We find that our intrinsic value measure explains between 8 and 22 percent of the variation in the heterogeneous response of asset prices to macroeconomic news announcements. When we estimate the importance of each of the three individual announcement characteristics separately, we find that our novel tardiness measure is the most important characteristic in explaining the announcement's price impact. The announcement's relation to fundamentals is less important, and the revision noise is insignificant. These results are consistent across the three primitives we use: GDP growth, GDP price deflator and FFTR. Importantly, our measure of tardiness explains the heterogeneous response of asset prices to macroeconomic announcements better than a previously used measure of the announcement's timing, the reporting lag of the announcement. This is due, in part, to the fact that our measure of tardiness takes into account both the announcement's release time and its relation to previously released announcements.

Our paper contributes to the literature by showing that the price response to a particular type of announcement cannot be analyzed in isolation ${ }^{3}$ The effect announcements have macroeconomic announcements on foreign exchange markets, the primitives should include both domestic and foreign monetary policy rates.

${ }^{3}$ Recent studies by Ehrmann and Sondermann $(2012)$ and Lapp and Pearce (2012) further support this view. 
on asset prices crucially depends on the information environment. When studying the link between asset prices and macroeconomic fundamentals, researchers need to account not only for the surprise component of an announcement but also for the announcement's relation to fundamentals and the timing of the announcement relative to other announcements. For example, researchers who only analyze the effect that final GDP announcements have on a particular asset price are likely to find that they have no impact on asset prices and may therefore wrongly conclude that there is a disconnect between asset prices and macroeconomic fundamentals. We show that asset prices do not react to final GDP announcements because, even though its relation to fundamentals is high, the timeliness of the GDP final release is very poor and, as a result, the intrinsic value of GDP final announcements relative to other announcements is small. Conversely, authors who estimate the effect that multiple macroeconomic announcements have on a particular asset price may conclude that macroeconomic announcements affect asset prices when in fact they find that only one or two announcements have a statistically significant impact. Our study suggests that announcements with a low intrinsic value should not affect asset prices.

Importantly, our analysis shows that the relationship between the intrinsic value of an announcement and its asset price impact is not perfect. In particular, we find that nonfarm payroll has the biggest impact on U.S. Treasury bond prices, yet it is not the announcement with the biggest intrinsic value. This raises the possibility that there may be an overreaction to certain announcements, such as nonfarm payroll, because of the coordination value of public information beyond its intrinsic value, as in the theoretical model of Morris and Shin (2002). Another possibility is that our definition of the intrinsic value of macroeconomic announcements needs to be further refined. For example, one could consider some other primitives. Furthermore, even though our method allows announcements to vary in their importance over time, one could impose more structure to better estimate the time-variation, as Bacchetta and van Wincoop (2013) and Goldberg and Grisse (2013) do, for example. We leave these extensions to future research. 
The remainder of this paper is organized as follows. In Section 2, we briefly discuss the relationship between an announcement's price impact and its intrinsic value, tardiness, revision noise, and relation to fundamentals within the context of noisy rational expectations models. In Section 3, we describe the data used in this study. In Section 4, we revisit the heterogeneous response of U.S. Treasury bond futures to macroeconomic news announcements. In Section 5, we explain the nowcasting framework we use to estimate our novel measures of intrinsic value, tardiness, revision noise, and relation to fundamentals of macroeconomic announcements. In Section 6, we formally investigate to what extent our measures help explain the heterogeneous impact of news on asset prices. We conclude in Section 7 .

\section{A Noisy Rational Expectations Model}

In this section, we briefly discuss the relationship between an announcement's price impact and its intrinsic value, tardiness, revision noise, and relation to fundamentals within the context of a noisy rational expectations model. For more details on these models, we refer the reader to, among many others, Grundy and McNichols (1989), Kim and Verrecchia (1991a)b), Kandel and Pearson (1995), Veronesi (2000), Hautsch and Hess (2007), and Hess and Niessen (2010).

We consider a market where a representative investor trades a risky asset at $t=1$ and 2 , and he consumes at $t=3$. Before observing any information at $t=0$, the representative investor assumes that the risky asset's payoff $\tilde{X}$ at $t=3$ is normally distributed with mean $\mu_{X 0}$ and precision (inverse of variance) $\rho_{X 0}$. In our empirical analysis, the risky asset is the U.S. Treasury bond futures. The payoff of this asset depends on the underlying state of the economy and, in the model, the representative investor revises his belief about the asset's payoff as he receives public (macroeconomic) information.

At $t=1$, the investor observes a signal of $\tilde{X}$ labeled as $\tilde{A}_{t}^{k}=\tilde{A}_{1}^{1}$, where the subscript $t=1$ indicates the release time of the announcement, and the superscript $k=1$ indicates 
different types of announcements (e.g., nonfarm payroll, industrial production, etc.). $4^{4}$ This signal is assumed to be equal to the asset payoff plus noise, $\tilde{A}_{1}^{1}=\tilde{X}+\tilde{\varepsilon}_{1}^{1}$, where $\tilde{\varepsilon}_{1}^{1}$ is normally distributed with mean 0 and precision $\rho_{A_{1}^{1}}$. Similarly, at $t=2$, investors observe another signal, $\tilde{A}_{2}^{2}=\tilde{X}+\tilde{\varepsilon}_{2}^{2}$, where $\tilde{\varepsilon}_{2}^{2}$ is normally distributed with mean 0 and precision $\rho_{A_{2}^{2}}$.

The representative investor has negative exponential utility with constant absolute risk aversion, $\gamma$, and maximizes his final consumption (wealth) at $t=3$. For simplicity, we assume that $\gamma=1$ and abstract away from private information and heterogeneous prior beliefs. The latter is required to generate trading volume (Kim and Verrecchia, 1991b), so prices move without any trading in our model.

At each time $t$, the rational investor estimates the conditional expectation and variance of the risky asset's payoff based on all available information. Since all signals are public, there is nothing additional to be learned from the price; hence the agent only needs to condition on the signals themselves. Using Bayes' rule, the asset's conditional expected payoff at time 1 is given by

$$
E\left[\tilde{X} \mid \tilde{A}_{1}^{1}\right] \equiv \mu_{X 1}=\rho_{X 1}^{-1}\left(\rho_{X 0} \mu_{X 0}+\rho_{A_{1}^{1}} \tilde{A}_{1}^{1}\right)
$$

where $\rho_{X 1}=\rho_{X 0}+\rho_{A_{1}^{1}}$ is the asset's conditional precision at time 1 . The weight the investor places on signal $\tilde{A}_{1}^{1}$ when updating his beliefs about the state of the economy, $\frac{\rho_{A_{1}^{1}}}{\rho_{X 1}}$, is what we label the intrinsic value of announcement 1.

Similarly, the conditional expected payoff at time 2 is

$$
\begin{aligned}
E\left[\tilde{X} \mid \tilde{A}_{1}^{1}, \tilde{A}_{2}^{2}\right] \equiv \mu_{X 2} & =\rho_{X 2}^{-1}\left(\rho_{X 0} \mu_{X 0}+\rho_{A_{1}^{1}} \tilde{A}_{1}^{1}+\rho_{A_{2}^{2}} \tilde{A}_{2}^{2}\right) \\
& =\rho_{X 2}^{-1}\left(\rho_{X 1} \mu_{X 1}+\rho_{A_{2}^{2}} \tilde{A}_{2}^{2}\right)
\end{aligned}
$$

where $\rho_{X 2}=\rho_{X 0}+\rho_{A_{1}^{1}}+\rho_{A_{2}^{2}}=\rho_{X 1}+\rho_{A_{2}^{2}}$ is the asset's conditional precision at time 2 . The weight the investor places on signal $\tilde{A}_{2}^{2}$ when updating his beliefs about the state of the

\footnotetext{
${ }^{4}$ In the empirical analysis, announcements have an additional subscript $p$ for the period the announcement refers to. For example, the nonfarm payroll announcement released in February provides employment information for January, hence the reference period is January and the release time is February. In this section, we omit this subscript because it is not relevant.
} 
economy, $\frac{\rho_{A_{2}^{2}}}{\rho_{X 2}}$, is the intrinsic value of announcement 2 .

At each time $t$, using the standard linear demand functions implied by the negative exponential utility function and imposing the market-clearing condition that demand must be equal to an exogenous supply of the risky asset (normally distributed), it is straightforward to show that prices are equal to the conditional expected payoffs: $p_{0}=E[\tilde{X}], \tilde{p}_{1}=E\left[\tilde{X} \mid \tilde{A}_{1}^{1}\right]$ and $\tilde{p}_{2}=E\left[\tilde{X} \mid \tilde{A}_{1}^{1}, \tilde{A}_{2}^{2}\right]$. Thus the expressions for the price change around both macroeconomic announcements are

$$
\tilde{p}_{1}-p_{0}=\frac{\rho_{A_{1}^{1}}}{\rho_{X 1}}\left(\tilde{A}_{1}^{1}-\mu_{X 0}\right)
$$

and

$$
\tilde{p}_{2}-\tilde{p}_{1}=\frac{\rho_{A_{2}^{2}}}{\rho_{X 2}}\left(\tilde{A}_{2}^{2}-\mu_{X 1}\right)
$$

The previous literature labels the weights $\frac{\rho_{A_{1}^{1}}}{\rho_{X 1}}$ and $\frac{\rho_{A_{2}^{2}}}{\rho_{X 2}}$ in equations (4) and (5) as the price impacts of announcement $A_{1}^{1}$ and $A_{2}^{2}$, respectively. In the model, what we label the intrinsic value of the announcements and the price impact of the announcements are exactly equal to each other. Below, we explain how we empirically estimate each of these weights and relate them to each other. We also explain other announcement characteristics: tardiness, revision noise, and relation to fundamentals.

\subsection{Intrinsic Value and Price Impact: Theory vs. Empirical Esti- mation}

In the theoretical model, the intrinsic value of announcements $\tilde{A}_{1}^{1}$ and $\tilde{A}_{2}^{2}$, respectively, are the weights in equations (1) and (2), $\frac{\rho_{A_{1}^{1}}}{\rho_{X 1}}$ and $\frac{\rho_{A_{2}^{2}}}{\rho_{X 2}}$. These are the weights the representative investor places on announcements $A_{1}^{1}$ and $A_{2}^{2}$ when he is updating his belief about the state of the economy. In our empirical analysis, we estimate these weights by assuming that the investor uses a Kalman filter to nowcast the state of the economy as proxied by GDP, GDP price deflator, or the FFTR. These weights, as we show below, depend on several announcement characteristics: timing, revision noise, and relation to fundamentals. Our 
label, intrinsic value, encompasses all of these characteristics.

Following previous studies, we estimate the price impact of announcements by regressing the log price change of U.S. Treasury bond futures on announcement surprises, $\tilde{S}_{t}^{k}=\tilde{A}_{t}^{k}-$ $\mu_{X(t-1)}$, where the expectation of the announcement, $\mu_{X(t-1)}$, is taken from Bloomberg. The coefficient in front of the announcement surprise is our price impact estimate. In the theoretical model we described, the price impact is exactly equal to the intrinsic value of the announcement. There are other theoretical models where the price impact is different from the intrinsic value. For example, in the theoretical model of Morris and Shin (2002), announcements have both an extrinsic and an intrinsic value. They define the intrinsic value of an announcement as the part that conveys information about fundamentals. In contrast, the extrinsic value has no direct bearing on fundamentals, yet it affects asset prices because the public signal serves as a coordination device. In our empirical estimation, the intrinsic value of the announcement and its price impact are positively correlated but are not exactly equal to each other. Our aim is to empirically relate these two measures in order to shed light on the reasons why some macroeconomic announcements have a bigger impact on asset prices than others.

\subsection{Tardiness: Theory vs. Empirical Estimation}

To analyze the effect of the announcement's timing on the price impact and intrinsic value weights, we assume that the two announcements discussed above are released at different times but are both equally precise: $\rho_{A_{1}^{1}}=\rho_{A_{2}^{2}} \equiv \rho_{A}$. We can thus re-write equations (4) and (5) as

$$
\tilde{p}_{1}-p_{0}=\frac{\rho_{A}}{\rho_{X 0}+\rho_{A}}\left(\tilde{A}_{1}^{1}-\mu_{X 0}\right)
$$

and

$$
\tilde{p}_{2}-\tilde{p}_{1}=\frac{\rho_{A}}{\rho_{X 0}+2 \rho_{A}}\left(\tilde{A}_{2}^{2}-\mu_{X 1}\right)
$$


It is unambiguous that the first announcement has a bigger price impact than the second, i.e., $\frac{\rho_{A}}{\rho_{X 0}+\rho_{A}}>\frac{\rho_{A}}{\rho_{X 0}+2 \rho_{A}}$. Since U.S. macroeconomic announcements follow a fairly rigid release schedule every month (see Figure 1), one would expect that, everything else held equal, early releases such as the Institute for Supply Management's Purchasing Managers' Index (ISM PMI), consumer confidence, and nonfarm payroll, should have a bigger price impact than later releases such as industrial production, factory orders, and business inventories.

Empirically, we define the announcement's tardiness as the percent loss in the nowcasting weight due to the announcement's release time. More precisely, the announcement's tardiness is the percent difference between two weights - the nowcasting weight put on the macroeconomic variable when we re-order it to be the first announcement released within a reference period minus its original nowcasting weight (intrinsic value) - divided by the announcement's original nowcasting weight. The bigger this difference is, the less timely the announcement is. This difference is large for announcements with large reporting lags and for those that are highly correlated with previously released announcements. Therefore, our measure takes into account both the reporting lag of the announcement and the information environment. In our empirical analysis, we relate the announcement's tardiness to its price impact.

\subsection{Revision Noise: Theory vs. Empirical Estimation}

To analyze the effect of the announcement's revision noise on the price impact weights, we assume that both announcements are released at the same time but allow the precision of the two announcements to differ: $\rho_{A_{1}^{1}} \neq \rho_{A_{1}^{2}}$. We therefore have

$$
\tilde{p}_{1}-p_{0}=\frac{\rho_{A_{1}^{1}}\left(\tilde{A}_{1}^{1}-\mu_{X 0}\right)+\rho_{A_{1}^{2}}\left(\tilde{A}_{1}^{2}-\mu_{X 0}\right)}{\rho_{X 0}+\rho_{A_{1}^{1}}+\rho_{A_{1}^{2}}} .
$$


We observe that if announcement 1 has higher precision than announcement 2, i.e., $\rho_{A_{1}^{1}}>\rho_{A_{1}^{2}}$, then announcement 1 has a bigger price impact than announcement 2,

$$
\frac{\rho_{A_{1}^{1}}}{\rho_{X 0}+\rho_{A_{1}^{1}}+\rho_{A_{1}^{2}}}>\frac{\rho_{A_{1}^{2}}}{\rho_{X 0}+\rho_{A_{1}^{1}}+\rho_{A_{1}^{2}}},
$$

because the denominator of both fractions is equal. Accordingly, when two announcements are released at the same time, e.g., nonfarm payroll and unemployment rate, the more precise (less revised) announcement will have a bigger price impact.

In the model, the precision $\rho_{A}$ is an ex-ante variable that gives investors a measure of expected noise, which is the likely "error" in the announcement in terms of its distance from the ex-post final value of $\tilde{X}$. Empirically, macroeconomic announcements undergo revisions following their initial release (Croushore, 2011), and these revisions can be interpreted as manifestations of this noise or imprecision.

Similar to our tardiness measure, we define an announcement's revision noise as the percent difference between two weights - the nowcasting weight put on the macroeconomic variable when we replace the actual value of the variable with its final revised value minus its intrinsic value nowcasting weight - divided by the announcement's intrinsic value nowcasting weight.

\subsection{Relation to Fundamentals: Theory vs. Empirical Estimation}

In the model, the noise $\tilde{\varepsilon}_{t}^{k}$ drives a wedge between $\tilde{X}$ and $\tilde{A}_{t}^{k}$. Empirically, some of this noise disappears over time with revisions. However, even the final revised value of $\tilde{A}_{t}^{k}$, denoted by

$\tilde{A}_{f}^{k}$, is only a noisy signal of $\tilde{X}$ with precision $\rho_{A_{f}^{k}}$. The revision noise of the $r^{t h}$ revision of this announcement is $\rho_{A_{r}^{k}}-\rho_{A_{f}^{k}}$, and it shrinks toward zero with every revision.

Announcements with equal tardiness and revision noise still differ in the noise component that never goes away - i.e., the precision of the final revised values $\rho_{A_{f}^{k}}-$ and this is the concept we label the announcement's relation to fundamentals. Our measure of an 
announcement's relation to fundamentals is related to the intrinsic value measure described above, but the key difference is that we force the announcement's nowcasting weight to be independent of its revision noise and its tardiness. To this end, we estimate the nowcasting weight by counterfactually re-ordering the announcement in question to be the first one released within a reference period and replacing it with its final revised value.

This measure allows us to compare the relation to fundamentals of two announcements by setting their tardiness to be identical and their revision noise to be the noise of their final release. Analogous to the argument in the previous subsection, a surprise in a final announcement $\tilde{A}_{f}^{k}$ with a larger $\rho_{A_{f}^{k}}$ would have a bigger price impact.

\section{Macroeconomic and Bond Price Data}

In our analysis, we use both macroeconomic and financial data. We have data on 36 U.S. macroeconomic series, listed in Table 1. For each of these, we record announcement dates, initial (actual) released values, market expectations, and final (revised) values. We label each announcement $A_{p, t}^{k}$ to indicate that the specific announcement is released at date $t$, refers to the value of the macroeconomic variable listed with index number $k$ in Table 1 . and its reference period is $p$ (e.g., nonfarm payroll released in February has January as its reference period). Real-time announcement data, expectations, and final revised numbers are from Bloomberg.

[Table 1 about here.]

[Figure 1 about here.]

We cover real activity, price, consumption, and investment data, and the release frequency varies from weekly to quarterly. The variables are presented in the order of their release time within each class according to the calendar timing of U.S. macroeconomic announcements across the month shown in Figure 1. Table 1 also provides some salient characteristics of these 
announcements: the announcement unit used in both the agency reports and the Bloomberg expectations, the time of the announcement release, and the number of available data releases for each quarterly, monthly or weekly variable. In addition to these 36 macroeconomic variables, we also collect data for the Federal Funds Target Rate (FFTR) and its release dates.

Our financial data consists of daily close-of-business prices for 2-, 5-, 10-, and 30-year U.S. Treasury bond futures contracts (all from Bloomberg). All prices are obtained for the most actively traded contract, which is usually the front-month contract. We focus on the bond market as opposed to the equity or foreign exchange markets because, as shown by the previous literature, the link between Treasury bond price movements and macroeconomic news announcements is simpler and stronger.

We consider two different samples in our paper. For the most part, the analysis and the tables refer to the period from January 1998 to March 2013. The beginning of the sample is limited by the availability of the market expectations. However, the nowcasting exercise from which we determine the weights, and for which we do not need expectations, uses data going back to 1990 as basis for our nowcasts starting in 1996. The nowcasts require a longer sample to ensure that, by 1998, the Kalman filter has converged and the announcement weights have stabilized.

\section{Asset Price Response to Macroeconomic Announce- ments}

We estimate the impact of macroeconomic announcements on asset prices by regressing the daily return of U.S. Treasury bond futures contracts $\left(2-, 5-, 10-\right.$, or 30-year), $r_{t}$, on macroeconomic news surprises. Specifically, we estimate the equation

$$
r_{t}=\alpha_{k}+\beta_{k} S_{p, t}^{k}+\varepsilon_{t},
$$


where $r_{t}$ is computed as $\log \left(p_{t} / p_{t-1}\right) \times 10,000$ based on the closing price $p_{t}$ on day $t 5^{5}$ The intercept $\alpha_{k}$ is a time-invariant, variable-specific announcement return, and the standardized announcement surprise $S_{p, t}^{k}$ is defined below. We use data from January 1998 to March 2013.

Following the literature, we define announcement surprises as the difference between announcement realizations and their corresponding expectations. Because units of measurement vary across macroeconomic announcements, we standardize the resulting surprises by dividing each of them by their sample standard deviation. The standardized news associated with the macroeconomic variable $k$ released at time $t$ with reference period $p$ is therefore computed as

$$
S_{p, t}^{k}=\frac{A_{p, t}^{k}-E_{p, t}^{k}}{\sigma_{S}^{k}}
$$

where $A_{p, t}^{k}$ is the announced value of variable $k$, and $E_{p, t}^{k}$ is the Bloomberg median forecast (expectation). The denominator, $\sigma_{S}^{k}$, is the sample standard deviation of $A_{p, t}^{k}-E_{p, t}^{k}$ estimated using the full sample of expectations and announcements. Equation (11) facilitates meaningful comparisons between responses of different asset price changes to different pieces of news. Since $\sigma_{S}^{k}$ is constant for any indicator $k$, the standardization does not have an impact on the statistical significance of the response estimates or the fit of the equation 10 . ${ }^{6}$

[Table 2 about here.]

Table 2 reports the results of equation 10 for each of the 36 macroeconomic announcements across four different assets. Our measure of the announcement's price impact is the slope coefficient on the standardized surprise, consistent with the noisy rational expectations model, but our results are qualitatively similar if we instead use the adjusted $R^{2}$ as measure

\footnotetext{
${ }^{5}$ We use daily returns instead of returns from a shorter time window around the announcement time (e.g., 5 minutes) to account for the price drifts ahead of several macroeconomic announcements documented in Kurov, Sancetta, Strasser, and Wolfe (2015). Nevertheless, our conclusions are similar if, instead of relating announcements' characteristics to daily price impacts, we relate those characteristics to 5-minute price impacts.

${ }^{6}$ Rigobon and Sack (2008) refine the econometric approach to measuring announcement surprises. By using identification through censoring, they estimate the share of the survey-based surprise due to noise. We choose not to follow their procedure because we allow the impact of news to vary with its noise. If we purge the noise from the announcement, we would underestimate the effect of noise on the price impact.
} 
of the announcement's price impact.

Consistent with prior literature, we find large differences in price impact coefficients across announcements. Similar to the findings in Fleming and Remolona (1997), Andersen et al. (2003), and Hess (2004), among others, we find that, within a general category of macroeconomic indicators, announcements released earlier tend to have greater impact than news released later. The most obvious example is that of GDP. The Bureau of Economic Analysis (BEA) releases three GDP figures: advance, preliminary, and final figures. The advance figure is released one month after the end of the quarter that the figure refers to (e.g., the first quarter GDP advance figure is generally announced at the end of April), the preliminary figure is released one month after that (e.g., in May), and the final figure another month thereafter (e.g., in June). Overall, GDP advance has the highest impact on U.S. Treasury bond price futures, regardless of whether we measure the impact by the $R^{2}$ or the slope coefficient. Similarly, the University of Michigan (UM) releases a preliminary figure of its consumer confidence index around the middle of the reference month and a final figure just before its end: The preliminary number also has a bigger impact on asset prices than the final number.

Hess and Niessen (2010), among others, show that the timeliness of an announcement is important. They show that the impact of the German Ifo business indicator on German bond futures prices diminished substantially when the German ZEW business indicator was created. Their explanation is that the ZEW index is highly correlated with the Ifo index, but the ZEW index is released before the Ifo index. Another study that highlights the importance of timing is that of Andersson, Ejsing, and von Landesberger (2008), who show that the reason for the small reaction of German bond prices to the aggregate German Consumer Price Index (CPI) announcement lies in the earlier release of CPI data for German states. Bond prices react significantly to surprises in the CPI of the two largest German states, effectively trading off the lower precision (by sampling only a part of Germany) with timing (by receiving the state figures four hours before the national figure). 
In the next section, we propose a novel measure of the timeliness (tardiness) of an announcement, which differs from the previously studied reporting lag of announcements, and introduce other announcement characteristics that may help us understand differences in the price impact of announcements.

\section{Measuring the Intrinsic Value of Announcements}

In this section, we describe our methodology for consistently measuring an announcement's intrinsic value, tardiness, revision noise, and relation to fundamentals. We start by setting up a nowcasting framework, which we subsequently use to define these four characteristics.

\subsection{Nowcasting GDP Growth, Inflation, and FFTR}

Motivated by Morris and Shin (2002) and noisy rational expectations models, we propose and estimate a novel empirical measure of an announcement's intrinsic value. We define the intrinsic value of an announcement as its importance in nowcasting three primitives: U.S. GDP, GDP price deflator, and the FFTR 7 Our approach to nowcasting is similar to the one formalized by Evans (2005) and Giannone, Reichlin, and Small (2008). Whenever new information arrives, the Kalman filter provides an estimate (nowcast) of the current state vector, which is then used to forecast the current level of the primitive of interest. By repeating this procedure for every primitive every time new information arrives, we obtain a time series of Kalman gains and regression coefficients, from which we calculate a time series of announcement weights 8 These announcement weights are the basis for our measures of intrinsic value, tardiness, revision noise, and relation to fundamentals, which we formally

\footnotetext{
${ }^{7}$ Macroeconomic forecasting with mixed-frequency data has received considerable attention in recent years, e.g., Andreou, Ghysels, and Kourtellos (2010). In terms of accuracy, the Kalman filter remains the method of choice, at the cost of being computationally more demanding than, for instance, mixed data sampling (MIDAS) regressions (Bai, Ghysels, and Wright, 2013). We follow the Kalman filter-based nowcasting approach not only because of accuracy but also because its data structure lends itself to traceable counterfactual exercises.

${ }^{8}$ Appendix A provides more details on data management, timing conventions, and nowcasting procedure.
} 
define below 9

We use the 36 macroeconomic announcements listed in Table 1 and the FFTR series, which we assume jointly capture the state of the U.S. economy. For nowcasting, we either use announcements in their original reporting units or transform the macroeconomic announcement series in order to approximate a linear relationship with the forecasting object 10 We use the original reporting units for indexes and variables reported in percent or percent changes. We transform variables reported in levels into percent changes. For example, the retail sales series, reported as a percent change, is not transformed, while the new home sales series is transformed from levels to percent change.

We use these 37 transformed announcements in a principal component analysis to calculate five factors: two global, one real, one nominal, and one forward-looking. We assume that at time $t$ the state vector of the economy, $\Phi_{p, t}=\left[\phi_{p, t}^{G 1}, \phi_{p, t}^{G 2}, \phi_{p, t}^{R}, \phi_{p, t}^{N}, \phi_{p, t}^{F}\right]$, follows a $\operatorname{VAR}(1)$ process, and our state equation is

$$
\Phi_{p, t}=B_{t} \Phi_{p-1, t}+C_{t} \nu_{p-1, t}
$$

where $\nu_{p, t} \sim W N\left(0, I_{2 \times 2}\right)$. Note that there are two time subscripts, $p$ and $t$. The state of the economy evolves at a monthly frequency, and the subscript $p$ identifies the state of the economy in reference period $p$. The subscript $t$ governs how much information is available about the current and past state vectors, and it identifies days within the month. This setup naturally maps the ever-evolving information set - with its missing values, revisions, and irregular announcement dates - into our data structure. As the information set grows with $t$, the estimates of $B_{t}$ and $C_{t}$ change as well.

\footnotetext{
${ }^{9}$ In contrast to the two seminal papers on nowcasting just mentioned, we use a larger set of factors and a larger set of time series, including information that is released at frequencies shorter than one month. Furthermore, we do not modify published data by, for instance, removing or replacing outliers with fitted values. Instead, we treat them as features of the data that our estimates should capture.

${ }^{10}$ More details on the transformation of each macroeconomic variable are collected in Appendix B, and Table B1 lists the 36 announcements, original reporting units, and the transformation if any.
} 
Our corresponding observation equation for a given information set $t$ is

$$
A_{p, t}=D_{t} \Phi_{p, t}+\varepsilon_{t}
$$

where $\varepsilon_{t} \sim W N\left(0, R_{N}\right)$, and $A_{p, t}=\left[A_{p, t}^{1}, \ldots, A_{p, t}^{N}\right]$ is the monthly vector of $N$ macroeconomic variables containing the values available at time $t[1] A_{p, t}^{k}$ contains only values announced on or before time $t$. We follow Giannone et al. (2008) in muting missing observations by setting the observation variance of missing announcements to a very large number.

From the Kalman filter we obtain the Kalman gain separately for each announcement for the most recent month for which the respective variable has data. Each variable therefore has an individually determined period of Kalman gain calculation. More specifically, at the release time of announcement $A_{p, t}^{k}$, we use the Kalman gain of announcement $k$ in period $p$. In general, this gain differs from the converged Kalman gain a few periods earlier, because some other announcements $k^{\prime} \neq k$ have at time $t$ not been released yet for period $p$ and therefore enter our setup with an infinite observation variance.

Next, we improve the estimates of the latent factors with the Kalman smoother. We then use a linear forecasting regression for GDP and the GDP price deflator and an ordered probit forecast for the FFTR to obtain coefficients on the latent factors at each point in time. We multiply the vector of coefficients that we obtained in this way with the Kalman gain matrix, which gives us a weight at each announcement time $t$. We label this weight "the nowcasting weight," which we use to construct our measures of intrinsic value, tardiness, revision noise, and relation to fundamentals.

\footnotetext{
${ }^{11}$ To be precise, we consolidate variables that are released piece by piece, namely GDP (advance, preliminary, final), GDP price deflator (advance, preliminary, final), and the University of Michigan consumer confidence index (preliminary, final); thus $N \leq 32$. However, in determining the weights, we keep track of what vintage (advance, preliminary, or final) they refer to. Older, preliminary values for these variables are replaced by the most recent vintage available at time $t$ in $A_{p, t}^{k}$.
} 


\subsection{Intrinsic Value}

We define the intrinsic value of macroeconomic variable $k$ with respect to target variable $X^{j}$ as the absolute value of the nowcasting weight put on macroeconomic variable $k$ at the time of its announcement. The intrinsic value can be thought of as the importance nowcasters place on the announcement when nowcasting the state of the economy.

[Table 3 about here.]

We report in columns 1,5 , and 9 of Table 3 the average intrinsic value for each macroeconomic variable when nowcasting GDP, the GDP price deflator, and the FFTR, respectively. Based on this metric, "forward-looking" announcements such as the consumer confidence indexes and the PMI indexes have large intrinsic values, which is consistent with the large price impact of these announcements.

\subsection{Tardiness}

A measure previously used in the literature for the timeliness of an announcement (e.g., Fleming and Remolona (1997)) is the median reporting lag, defined as the number of days from the end of the period the announcement refers to (end of the reference quarter, month, or week) and its release date ${ }^{12}$ We report this measure in column 13 of Table 3, which matches the announcement calendar shown in Figure 1. According to this measure, the most timely announcement is the UM consumer confidence index (preliminary), followed by the Philadelphia Fed index, the UM consumer confidence index (final), the Conference Board consumer confidence index, the ISM PMI, and the employment report (unemployment rate, nonfarm payroll, and average hourly earnings). The ordering of the announcements

\footnotetext{
${ }^{12}$ Note that there is a difference between the reporting lag as we define it and the difference between the end of the survey period and the announcement date. At the Bureau of Labor Statistics, "employment data refer to persons on establishment payrolls who received pay for any part of the pay period that includes the $12^{\text {th }}$ of the month" (http://www.bls.gov/web/cestn1.htm). This means that taking the end of the month as the end of the reference period is not exact, because the surveying stopped much earlier in the month.
} 
throughout the month has been fairly constant over the past two decades, with idiosyncratic deviations happening due to release mistakes, government shutdowns, strikes, or holidays.

One important drawback of this measure of tardiness is that it is a linear function of time, so an improvement in timeliness of, say, six days is the same for an early and a late announcement. However, we expect a 7-day reporting lag announcement to gain more from moving up its release date six days than a 21-day reporting lag announcement moving up six days. This is because the 7-day reporting lag announcement will now be the first announcement while the 21 -day reporting lag will be the $15^{\text {th }}$ announcement, and it is likely that the earlier releases have already conveyed sufficient information. The new measure we propose takes into account the position of the announcement when computing the gain in timeliness.

To compute our measure for macroeconomic announcement $k$, we create a dataset of counterfactually reordered observations. For each reference period, we identify the earliest announcement and we move the release of announcement $k$ to one second before the earliest announcement. The earliest announcement for each reference period is either the unemployment rate, the consumer confidence index, or the ISM PMI in the earlier part of our sample; and either the Philadelphia Fed index or the UM consumer confidence preliminary announcement after 1997. For example, consider the durable goods orders announcement on December 23, 2004, referring to November 2004. The first release referring to November 2004 in our sample is the University of Michigan consumer confidence index preliminary announced on November $12^{\text {th }}, 2004$ at 10:00 am. We therefore move this durable goods orders announcement to November 12, 2004, at 9:59:59 am. We repeat this procedure for each durable goods orders release. As a result, we end up with a dataset that is identical to the original one except that the releases of one variable, the durable goods orders, have been reordered. We then re-estimate the factor model and determine the new weights according to the algorithm described in Section 5.1. The percent change between the weights from the 
re-ordered dataset and the original weights is our tardiness measure. ${ }^{13}$

The ordering of our tardiness measures given in columns 2, 6, and 10 of Table 3 is positively correlated with the median reporting lag shown in column 13. The correlation is $0.76,0.62$, and 0.58 when the target variables are GDP, GDP price deflator, and FFTR, respectively. Importantly, however, two announcements released at the same time might differ in their correlation with earlier announcements. Therefore, if both are moved to the same earlier date, then the one that is more correlated with earlier announcements will have a higher value for tardiness. That is, the one more correlated with the announcements released beforehand suffers more in terms of nowcasting weight by being released later, because the same information is partially released through the earlier correlated announcements. In other words, such an announcement would gain more by being released earlier. For example, the unemployment rate and nonfarm payroll announcements are released at the same time on the same day. However, our measure indicates that the unemployment rate is less timely than the nonfarm payroll report. The reason is that the unemployment rate gains more from being released earlier because it is highly correlated with the UM consumer confidence index (-0.84 correlation) and the Philadelphia Fed index (-0.72 correlation), while the nonfarm payroll release gains less from being released earlier because its correlation with these announcements is lower (0.47 and 0.46, respectively) ${ }^{14}$ Interestingly, nonfarm payroll has a bigger impact on asset prices than the unemployment report. Our measure indicates that one potential explanation for this phenomenon is that the nonfarm payroll report is more timely. In our empirical analysis, we show that our tardiness measure can indeed better explain the

\footnotetext{
${ }^{13}$ More precisely: tardiness $_{t} \equiv \frac{\text { weights }_{R A, t}-\text { weights }_{A, t}}{\text { weights }_{A, t}} \times \mathbb{1}\left(\right.$ weights $_{R A, t} \geq$ weights $\left._{A, t}\right)$, where $A$ labels the actual first announcement and $R A$ the reordered ones. $\mathbb{1}\left(\right.$ weights $_{R A, t} \geq$ weights $_{A, t}$ ) indicates that, in the rare occasions when the weight we obtain by re-ordering the data set is smaller than the weight we obtained using the original dataset, we set this percent change to zero. Our results are qualitatively similar if we allow the percent change to be negative.

${ }^{14}$ We conjecture that the unemployment rate may be more correlated with the University of Michigan consumer confidence survey because survey respondents have a better sense of the unemployment rate than nonfarm payroll, and this is reflected in their answers to the following five questions: appraisal of current business conditions, appraisal of current employment conditions, expectations regarding business conditions six months hence, expectations regarding employment conditions six months hence, and respondents expectations regarding their total family income six months hence.
} 
heterogeneous response to announcements than reporting lag can.

\subsection{Revision Noise}

Macroeconomic announcements undergo significant revisions during the months and years following their initial release. One way to capture the imprecision stemming from these future revisions for a given reference period $p$ is to take the absolute value of the difference between the final (available) value and the initially announced value:

$$
\frac{\left|F_{p}^{k}-A_{p, t}^{k}\right|}{\sigma_{\left|F_{p}^{k}-A_{p, t}^{k}\right|}},
$$

where $F_{p}^{k}$ is the final revised value of macroeconomic indicator $k$, with reference period $p .^{15}$ The final revised values are taken from Bloomberg. Whenever possible, we compared these values with the December 2013 vintage available from each reporting agency's website, and the two numbers were the same. For ease of interpretation of our regression results, we standardize the absolute revision by its standard deviation for each respective indicator $k$.

In the last column of Table 3, we report the average for each macroeconomic variable $k$. Macroeconomic announcements differ considerably in the magnitude of the revisions they undergo. On one end of the spectrum stand the government budget deficit and consumer credit, which are barely revised at all, meaning their announcements are essentially free of revision noise. On the other end of the spectrum stand capacity utilization and industrial production, which are revised heavily.

One drawback of this measure is that it does not take into account the possibility that the revised (final) number is less useful in nowcasting target variables than the original (first-released) number. For example, Orphanides (2001) shows that the first release of the

\footnotetext{
${ }^{15}$ This definition is used by Gilbert (2011), except that we standardize the measure. This definition includes both sample and benchmark revisions and assumes that the last available value reflects the "true" situation. As a robustness check, we also use the first-available sample revisions, similar to Gilbert (2011), for the variables available in the Federal Reserve Bank of Philadelphia's Real-Time Data Set and Bloomberg. These variables are GDP, GDP price deflator, unemployment, nonfarm payroll, housing starts, CPI, PPI, industrial production, and capacity utilization. The results are qualitatively similar.
} 
GDP price deflator and GDP are better predictors of the Federal Open Market Committee's (FOMC) decisions than the final revised numbers. To address this issue, we construct an alternative measure of revision noise that takes into account how useful final revised numbers are in nowcasting target variables. Similar to our tardiness measure, to estimate the revision noise of announcement $k$, we construct a counterfactual dataset where announcement $k$ is replaced by its final values. We then re-estimate the factor model and estimate the new weights. The percent change between the weights for the counterfactual dataset and the original weights represents our revision noise measure. ${ }^{16}$

We observe a disconnect between the ordering of our revision noise measure given in columns 3, 7, and 11 of Table 3 and the simpler measure of revision noise from equation (14) shown in column 14. The correlation is close to zero, in part reflecting the fact that final revised numbers are less useful for nowcasting, consistent with Orphanides (2001). The previously used revision noise measure captures only the magnitude of the revision but not the relevance of a revision, which is included in our measure. So, for example, while the UM consumer confidence index is heavily revised, and hence has a big revision noise under the definition of equation (14), we find that the preliminary released figure better predicts the FFTR, and therefore we get a small value for our measure of revision noise.

\subsection{Relation to Fundamentals}

In the noisy rational expectations model, market participants put more weight on announcements that are more closely related to fundamentals, independent of their timing and revision noise. To capture this idea, we define the relation to fundamentals as the usefulness of a final announcement, standardized to a common release time, in our nowcasting exercise. Specifically, to estimate this measure for macroeconomic announcement $k$, we replace announcement $k$ with its final revised value (to remove revision noise) and reorder its announcement

\footnotetext{
${ }^{16}$ More precisely: noise $_{t} \equiv \frac{\text { weights }_{F, t}-\text { weights }}{\text { weights }_{A, t}} \times \mathbb{1}\left(\right.$ weights $_{F, t} \geq$ weights $\left.{ }_{A, t}\right)$, where $A$ labels the actual first announcements and $F$ the final announcement values at first release. As before, we replace the difference with a zero if the final revised value is less useful in nowcasting the target variable than its first release is.
} 
time so that it is the first release in each reference cycle (to control for tardiness). We then re-estimate the factor model and estimate the new weights.

We report the average of this measure in columns 4, 8, and 12 of Table 3 , and we observe that the announcement most closely related to fundamentals is trade balance, followed by capacity utilization, the unemployment rate, the Philadelphia Fed index, and initial unemployment claims. Controlling for timing and revision noise, these variables are the most useful for nowcasting the fundamentals that we consider - namely GDP, the GDP price deflator, and the FFTR - and in this sense are most related to these fundamentals.

\section{Relating the Price Impact to the Announcement's Characteristics}

In this section, we relate our new measures of the announcements' intrinsic value, tardiness, revision noise, and relation to fundamentals to their price impact. We first examine whether our measures affect the impact of announcement surprises on asset prices using the full sample. Then we investigate whether our measures explain the cross-section of impact coefficients.

\subsection{Direct Impact on Asset Returns}

We re-estimate equation 10 while constraining all announcement surprises to have the same effect on price changes and allowing the surprise to differ only depending on the announcement's intrinsic value, tardiness, revision noise, and relation to fundamentals. Specifically, we estimate the following equation:

$$
r_{t}=\beta_{0}+\beta_{S} S_{t}+\beta_{S, X} S_{t} X_{t}+\varepsilon_{t}
$$


where $\varepsilon_{t} \mid w_{t-1} \sim \operatorname{iid} N(0,1)$. As previously defined, $r_{t}$ is the daily return of the U.S. Treasury bond futures contract at day $t$. We force the sign of the surprise, $S_{t} \equiv S_{p, t}^{k}$, to be consistent across announcements. To this end, we multiply surprises by -1 , except for the unemployment rate and initial unemployment claims. Thus, a positive surprise indicates a deterioration of the macroeconomy and is associated with an increase in U.S Treasury bond futures prices. The announcement property, $X_{t} \equiv X_{p, t}^{k}$, is either the announcement's intrinsic value (I), tardiness $(\mathrm{T})$, revision noise $(\mathrm{N})$, or relation to fundamentals $(\mathrm{F}) \cdot{ }^{17}$

Columns 1 to 4 in Tables 4, 5, and 6 show the results with each different characteristic included in the regression in isolation, and column 6 shows all three characteristics competing against each other. There is one table per nowcasted primitive: Table 4 for GDP, Table 5 for the GDP price deflator, and Table 6 for the FFTR.

[Table 4 about here.]

[Table 5 about here.]

[Table 6 about here.]

Column 2 shows that, across forecasting targets, the intrinsic value of an announcement has an economic and statistically significant effect on the asset price impact of that announcement. The sign of the coefficient is consistent with the noisy rational expectations model described in Section 2, the bigger the intrinsic value of the announcement is, the bigger the price impact is. More precisely, increasing the intrinsic value of an announcement by one standard deviation increases the impact of the surprise by more than one half when the nowcasting target is GDP. For example, a one-standard deviation surprise in an announcement, with an average intrinsic value of zero, increases 5-year bond futures prices

\footnotetext{
${ }^{17}$ We standardize and smooth all four characteristics. Specifically, we divide each characteristic by its standard deviation estimated across all announcements and all times. This eases the interpretation of the coefficient estimates. In addition, we smooth the weights by taking a 12-month backward-looking moving average. The assumption is that, in calculating the importance of an announcement, investors take the average importance over the past year.
} 
by 2.8 basis points when the nowcasting target is GDP (Table 4). If we increase the intrinsic value of this announcement by one standard deviation, a surprise on this announcement will increase 5-year bond futures prices by $4.58(2.828+1.766)$ basis points, which is a 63 percent increase in the price impact. The increase in the impact is more than one third when the nowcasting target is either the GDP price deflator or the FFTR.

Columns 3 through 6 suggest that, across forecasting targets, tardiness is the most relevant announcement characteristic; relation to fundamentals is less so; and revision noise is, most of the time, statistically insignificant. Column 6 suggests that decreasing the tardiness of an announcement by one standard deviation increases the impact of the surprise by about 30 percent across all nowcasting targets, consistent with the theoretical model described in Section 2. Increasing the relation to fundamentals of an announcement by one standard deviation increases the impact of the surprise by about 20 percent when the nowcasting target is GDP. Revision noise is statistically insignificant across most maturities and nowcasting targets, especially when the nowcast target is the FFTR.

\subsection{Determinants of Average Surprise Impact}

In the previous section, we found that tardiness is the announcement characteristic that affects the impact of announcement surprises on asset prices the most. In this section, we investigate whether our measures explain the cross-section of impact coefficients and how they compare with the time-invariant announcement characteristics previously used in the literature, such as the announcement's reporting lag. In this cross-sectional analysis, we use a two-step estimation procedure. First, we estimate the asset price impact, $\beta_{k}$, using equation 10 . Then we estimate the following equation:

$$
\beta_{k}=\alpha_{0}+\alpha_{X} X_{k}+\varepsilon_{k},
$$

where $X_{k}$ is the average over time of our measure of the announcement's intrinsic value. 
In columns 1 through 3 in Table 7 we show the results when we use GDP, the GDP price deflator, and the FFTR as our nowcasting target, respectively. We find that our intrinsic value measure explains from 8 to 22 percent of the variation in the price impact of announcement surprises, as indicated by the adjusted $R^{2}$. Interestingly, using GDP as the nowcasting target appears to be more useful in explaining the variation in price impact than using the GDP price deflator. This finding may be an artifact of the sample period we analyze. During our sample period, inflation was relatively low and inflation expectations may not have played a big role in nominal U.S. Treasury bond prices. Using GDP as the nowcasting target is also more useful in explaining the variation than using the FFTR. This may not be surprising because the impact of news about the FFTR on nominal U.S. Treasury bonds includes offsetting effects on real and inflation components, as shown by Beechey and Wright (2009). Moreover, our sample includes the zero-lower-bound period, which may complicate the analysis.

\section{[Table 7 about here.]}

In columns 2 through 4 in Table 8, we report the estimates of equation (16) where $X_{k}$ is the average over time of our measure of the announcement's tardiness, revision noise, and relation to fundamentals, respectively, when we use GDP as the nowcasting target. Our results are qualitatively similar when we use the other two nowcasting targets (the GDP price deflator and the FFTR). The advantage of the cross-sectional estimation is that it allows us to compare our measures with previously analyzed announcement characteristics, such as reporting lag, which has little or no time variation. Accordingly, in columns 5 through 7 , we report the estimates of equation (16) where $X_{k}$ are the simpler and previously analyzed announcement characteristics: the correlation of the announcement with the nowcasting target (GDP) using the full sample (as a measure of the relation to fundamentals), the announcement's reporting lag (as a measure of tardiness), and the revision noise measure given by equation (14). We include each of these characteristics separately because our sample is small, with only 36 observations (one observation for each announcement). 
[Table 8 about here.]

The table shows that tardiness is the single most important variable in explaining the asset price impact of news announcements, which is consistent with our previous results. It explains about 20 percent of the variation in asset price impact coefficients. Our other two measures, relation to fundamentals and revision noise, have the correct sign but are statistical insignificant. Importantly, our measure of tardiness explains the variation in $\beta_{k}$ coefficients better than the reporting lag of the announcement. The adjusted $R^{2}$ when we use our measure of tardiness is twice as big as the $R^{2}$ when we use reporting lag. This is in part due to the fact that our measure takes into account both the timeliness of the announcement and the relation of the announcement to previously released announcements.

Both our measure of the relation to fundamentals and the correlation between announcement $k$ and the nowcasting target (in this case GDP) are statistically insignificant across most maturities. Interestingly, the previously used measure of revision noise given by equation (14) is statistically significant, but the sign is the opposite of what our theoretical model would predict. According to this measure, announcements that undergo more revisions have a higher price impact. The counter-intuitive sign suggests that one should not consider the magnitude of the revisions in isolation; instead, one should consider both the magnitude of the revision and the relevance of the revision.

\section{Conclusion}

In this paper we propose and estimate novel measures of the intrinsic value of announcements. Our definition is based on the announcement's ability to nowcast GDP growth, the GDP price deflator, and the Federal Funds Target Rate (FFTR). We decompose this intrinsic value into three separate announcement characteristics: relation to fundamentals, tardiness, and revision noise. We find that tardiness - the loss of intrinsic value due to the time lag between the reference period and the announcement release time - is the most significant 
characteristic in explaining the variation in the announcements' asset price impact. Importantly, our novel measure explains more of the variation than the previously used measure of an announcements' timeliness, namely its reporting lag.

Our study offers two additional takeaways. First, the price response to a particular type of announcement cannot be analyzed in isolation. The effect announcements have on asset prices crucially depends on the information environment. Second, our analysis shows that the relationship between the intrinsic value of an announcement and its asset price impact is not perfect. In particular, we find that nonfarm payroll has the biggest impact on U.S. Treasury bond prices, yet it is not the announcement with the biggest intrinsic value. This raises the possibility that there may be an overreaction to certain announcements. 
Table 1. Characteristics of Macroeconomic Announcements

The table displays the 36 U.S. macroeconomic variables analyzed in the paper, along with the announcement unit used in both the agency reports and the Bloomberg expectations, the time of the announcement release (Eastern Time), and the number of available data releases. Our sample covers January 1998 to March 2013.

\begin{tabular}{|c|c|c|c|c|}
\hline$k$ & Announcement & Unit & Rel. Time & Obs. \\
\hline \multicolumn{5}{|c|}{ Quarterly Announcements } \\
\hline & Real Activity & & & \\
\hline 1 & GDP advance & $\%$ change & $8: 30$ & 70 \\
\hline 2 & GDP preliminary & $\%$ change & $8: 30$ & 69 \\
\hline \multirow[t]{2}{*}{3} & GDP final & $\%$ change & $8: 30$ & 71 \\
\hline & Prices & & & \\
\hline 4 & GDP price deflator advance & $\%$ change & $8: 30$ & 70 \\
\hline 5 & GDP price deflator preliminary & $\%$ change & $8: 30$ & 69 \\
\hline 6 & GDP price deflator final & $\%$ change & $8: 30$ & 71 \\
\hline \multicolumn{5}{|c|}{ Monthly Announcements } \\
\hline & Real Activity & & & \\
\hline 7 & Unemployment report & $\%$ & $8: 30$ & 207 \\
\hline 8 & Nonfarm payroll employment & change & $8: 30$ & 207 \\
\hline 9 & Retail sales & $\%$ change & $8: 30$ & 207 \\
\hline 10 & Retail sales less automobiles & $\%$ change & $8: 30$ & 207 \\
\hline 11 & Industrial production & $\%$ change & $9: 15$ & 207 \\
\hline 12 & Capacity utilization & $\%$ & $9: 15$ & 207 \\
\hline 13 & Personal income & $\%$ change & $8: 30 / 10: 00$ & 205 \\
\hline \multirow[t]{2}{*}{14} & Consumer credit & change & $15: 00$ & 207 \\
\hline & Consumption & & & \\
\hline 15 & Personal consumption expenditures & $\%$ change & $8: 30$ & 206 \\
\hline \multirow[t]{2}{*}{16} & New home sales & level & $10: 00$ & 206 \\
\hline & Investment & & & \\
\hline 17 & Durable goods orders & $\%$ change & $8: 30 / 9: 00 / 10: 00$ & 206 \\
\hline 18 & Construction spending & $\%$ change & $10: 00$ & 206 \\
\hline 19 & Factory orders & $\%$ change & $10: 00$ & 206 \\
\hline \multirow{2}{*}{20} & Business inventories & $\%$ change & $8: 30 / 10: 00$ & 207 \\
\hline & Government Purchases & & & \\
\hline \multirow[t]{2}{*}{21} & Government budget deficit & level & 14:00 & 206 \\
\hline & Net Exports & & & \\
\hline \multirow[t]{2}{*}{22} & Trade balance & level & $8: 30$ & 208 \\
\hline & Prices & & & \\
\hline 23 & Average hourly earnings & $\%$ change & $8: 30$ & 207 \\
\hline 24 & Producer price index & $\%$ change & $8: 30$ & 207 \\
\hline 25 & Core producer price index & $\%$ change & $8: 30$ & 207 \\
\hline 26 & Consumer price index & $\%$ change & $8: 30$ & 207 \\
\hline \multirow[t]{2}{*}{27} & Core consumer price index & $\%$ change & $8: 30$ & 207 \\
\hline & Forward Looking & & & \\
\hline 28 & U. Michigan consumer confidence preliminary & index & 10:00 & 166 \\
\hline 29 & Philadelphia Fed manufacturing index & index & 10:00 & 194 \\
\hline 30 & U. Michigan consumer confidence final & index & 10:00 & 167 \\
\hline 31 & Conference Board consumer confidence & index & 10:00 & 206 \\
\hline 32 & (ISM-)Chicago Purchasing Managers Index (PMI) & index & 10:00 & 196 \\
\hline 33 & ISM* Manufacturing PMI & index & $9: 15 / 10: 00$ & 207 \\
\hline 34 & Housing starts & level & $8: 30$ & 208 \\
\hline 35 & Index of leading indicators & $\%$ change & $8: 30 / 10: 00$ & 208 \\
\hline \multicolumn{5}{|c|}{ Weekly Announcements } \\
\hline 36 & Initial unemployment claims & level & $8: 30$ & 898 \\
\hline
\end{tabular}




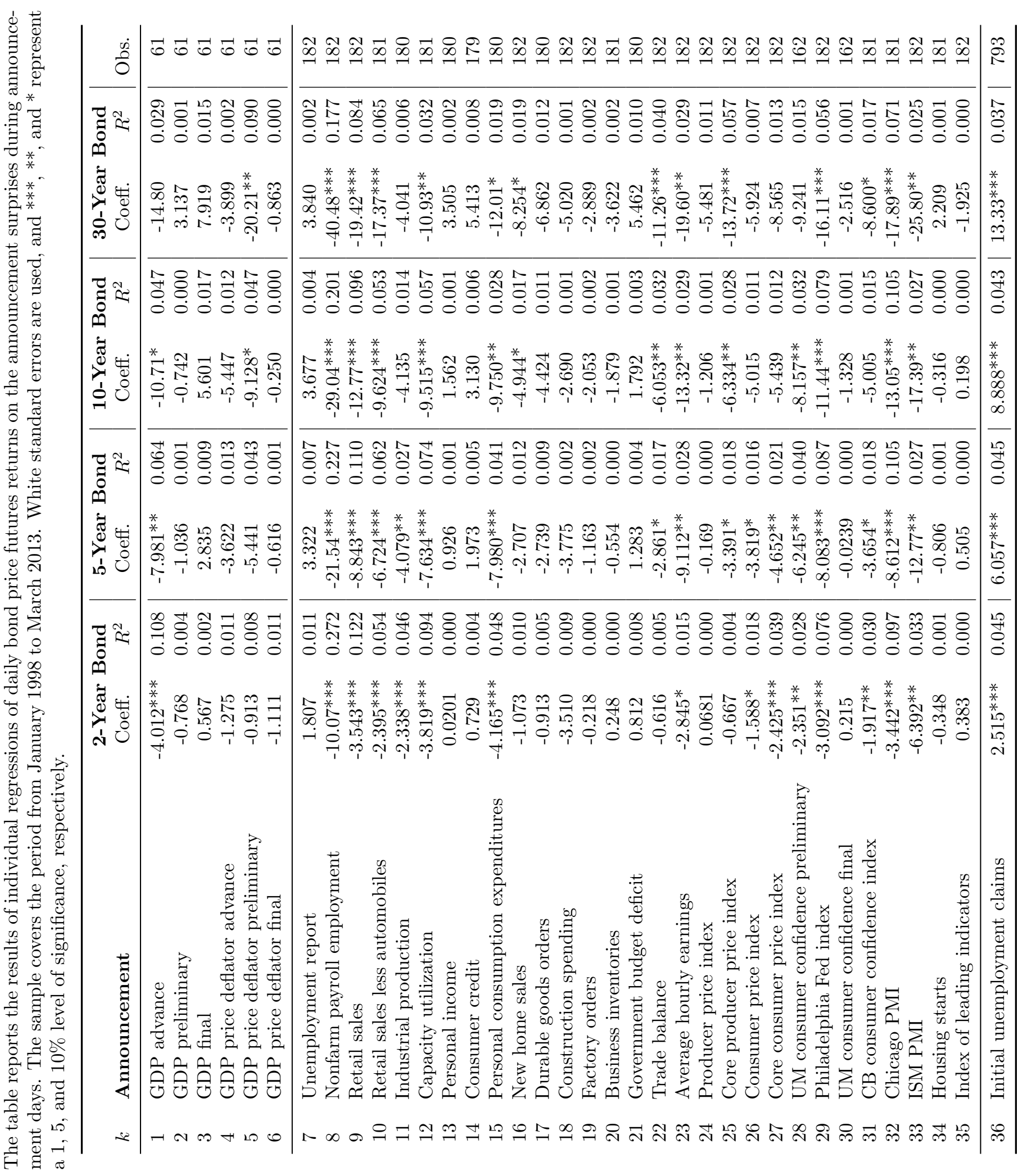




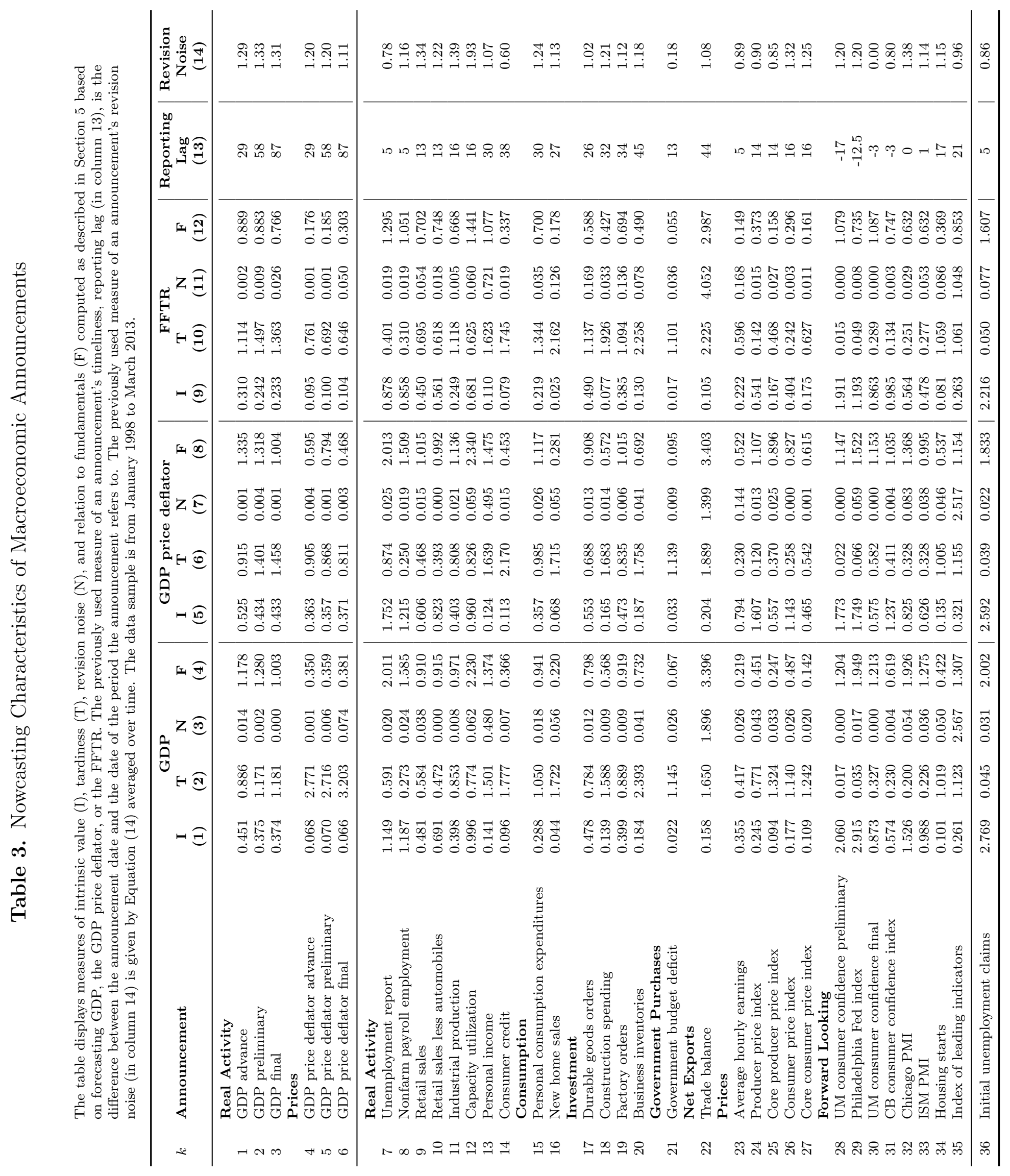




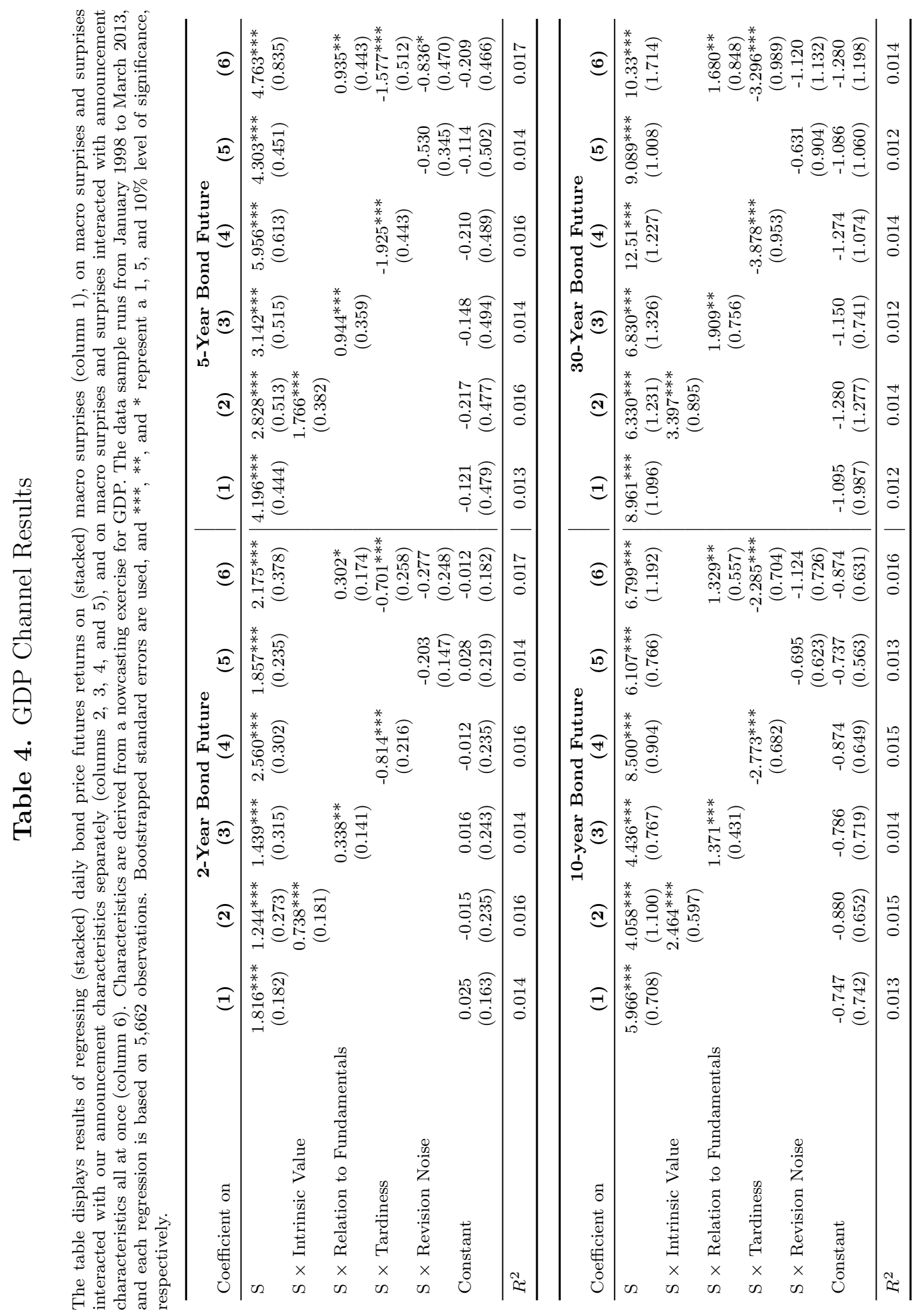




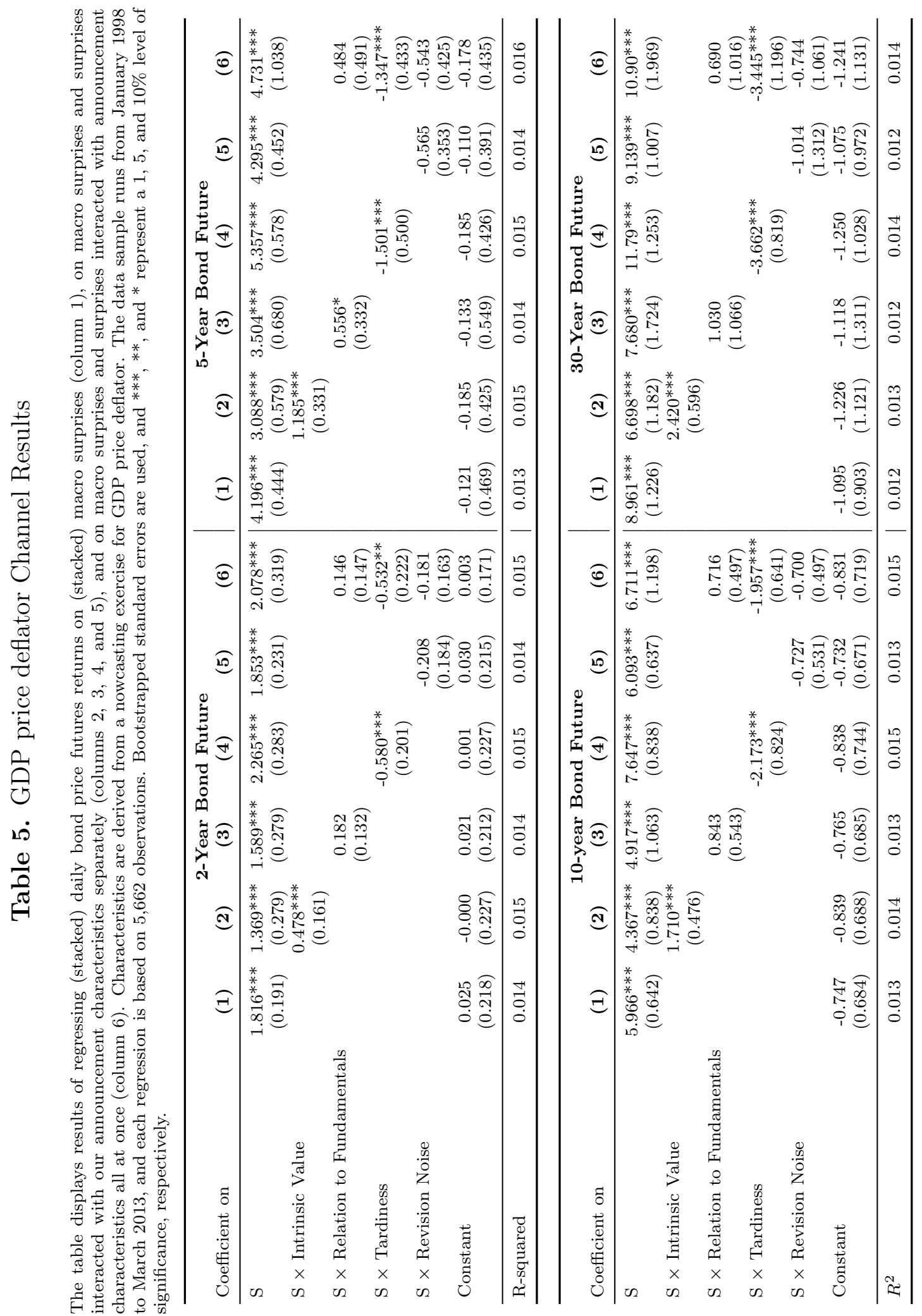




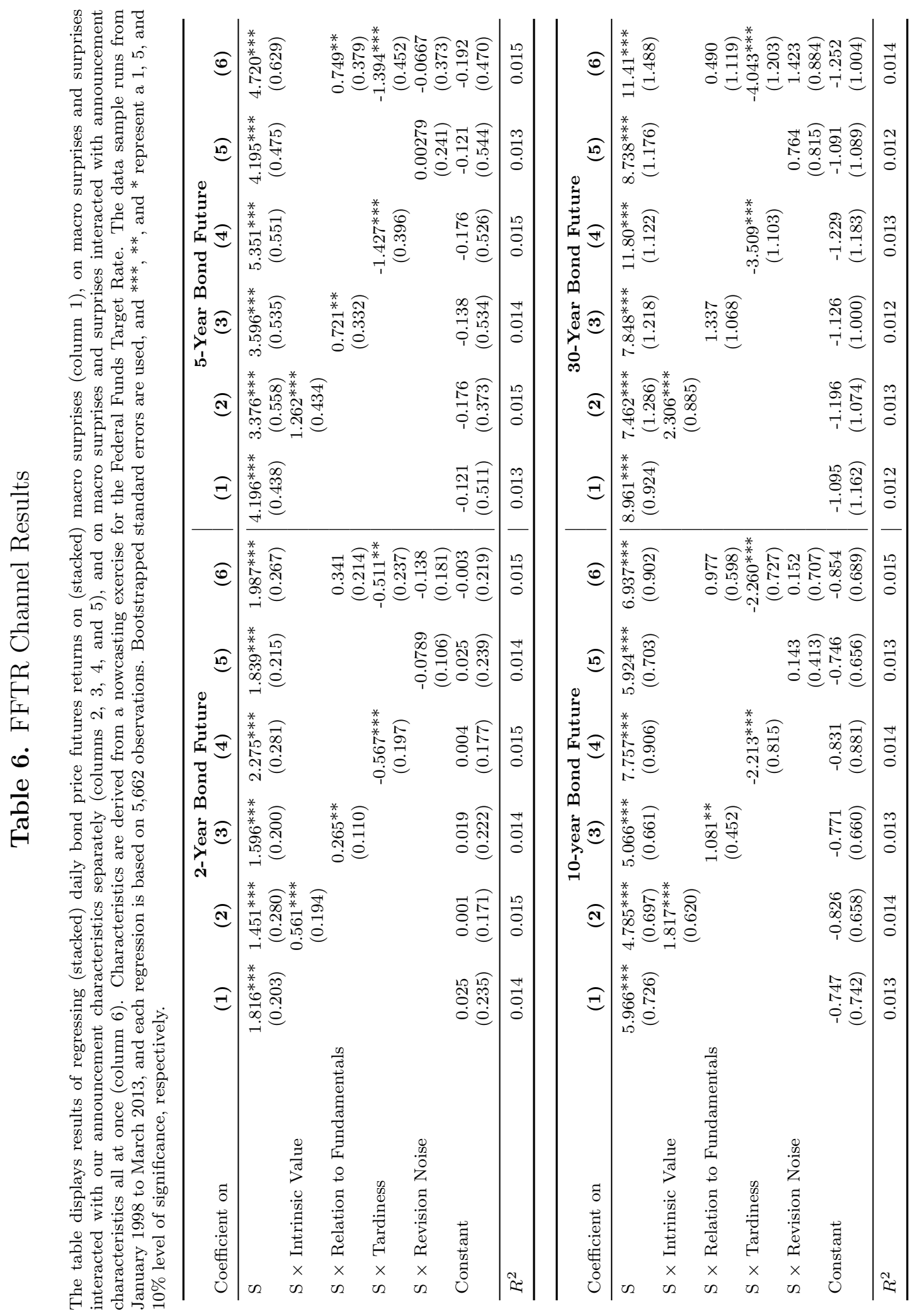




\section{Table 7. Price Impact and Intrinsic Value}

The table displays results of regressing the estimated $\beta_{k}$ coefficients in equation 10 on the announcement's intrinsic value derived from nowcasting GDP, the GDP price deflator, and the Federal Funds Target Rate. The sample covers the period from January 1998 to March 2013, and each regression is based on 36 observations. White standard errors are used, and $* * *, * *$, and $*$ represent a 1,5 , and $10 \%$ level of significance, respectively.

\section{2-Year Bond Future}

\begin{tabular}{|c|c|c|c|}
\hline & \multicolumn{3}{|c|}{ Nowcasting Target } \\
\hline Coefficient on & $\begin{array}{l}\text { GDP } \\
(1)\end{array}$ & $\begin{array}{c}\text { GDP } \\
\text { Deflator } \\
(2)\end{array}$ & $\begin{array}{l}\text { FFTR } \\
(3)\end{array}$ \\
\hline Intrinsic Value & $\begin{array}{c}0.867^{* * *} \\
(0.314)\end{array}$ & $\begin{array}{l}0.629^{*} \\
(0.330)\end{array}$ & $\begin{array}{c}0.683^{* *} \\
(0.327)\end{array}$ \\
\hline Constant & $\begin{array}{c}1.293^{* * *} \\
(0.409)\end{array}$ & $\begin{array}{l}1.282^{* *} \\
(0.511)\end{array}$ & $\begin{array}{c}1.368^{* * *} \\
(0.453)\end{array}$ \\
\hline$R^{2}$ & 0.18 & 0.10 & 0.11 \\
\hline \multicolumn{4}{|c|}{ 5-Year Bond Future } \\
\hline & \multicolumn{3}{|c|}{ Nowcasting Target } \\
\hline Coefficient on & $\begin{array}{l}\text { GDP } \\
(1)\end{array}$ & $\begin{array}{c}\text { GDP } \\
\text { Deflator } \\
(2)\end{array}$ & $\begin{array}{c}\text { FFTR } \\
(3)\end{array}$ \\
\hline Intrinsic Value & $\begin{array}{c}2.016^{* * *} \\
(0.648)\end{array}$ & $\begin{array}{c}1.507^{* *} \\
(0.688)\end{array}$ & $\begin{array}{c}1.561^{* *} \\
(0.684)\end{array}$ \\
\hline Constant & $\begin{array}{c}2.935^{* * *} \\
(0.845)\end{array}$ & $\begin{array}{c}2.856^{* *} \\
(1.064)\end{array}$ & $\begin{array}{c}3.134^{* * *} \\
(0.948)\end{array}$ \\
\hline$R^{2}$ & 0.22 & 0.12 & 0.13 \\
\hline
\end{tabular}

\begin{tabular}{l|ccc}
\multicolumn{4}{c}{ 10-Year Bond Future } \\
\hline \multirow{2}{*}{ Coefficient on } & $\begin{array}{c}\text { NDPcasting Target } \\
\text { GD }\end{array}$ & $\begin{array}{c}\text { GDP } \\
\text { Deflator } \\
(2)\end{array}$ & $\begin{array}{c}\text { FFTR } \\
(3)\end{array}$ \\
\hline Intrinsic Value & $\begin{array}{c}2.735^{* * *} \\
(0.882)\end{array}$ & $\begin{array}{c}2.031^{* *} \\
(0.937)\end{array}$ & $\begin{array}{c}2.093^{* *} \\
(0.933)\end{array}$ \\
Constant & $\begin{array}{c}4.224^{* * *} \\
(1.150)\end{array}$ & $\begin{array}{c}4.133^{* * *} \\
(1.450)\end{array}$ & $\begin{array}{c}4.517^{* * *} \\
(1.292)\end{array}$ \\
\hline$R^{2}$ & 0.22 & 0.12 & 0.13 \\
\hline
\end{tabular}

30-Year Bond Future

\begin{tabular}{l|ccc}
\hline & \multicolumn{3}{|c}{ Nowcasting Target } \\
\hline \multirow{3}{*}{ Coefficient on } & $\begin{array}{c}\text { GDP } \\
(1)\end{array}$ & $\begin{array}{c}\text { Geflator } \\
(2)\end{array}$ & $\begin{array}{c}\text { FFTR } \\
(3)\end{array}$ \\
\hline Intrinsic Value & $\begin{array}{c}3.215^{* *} \\
(1.294)\end{array}$ & $\begin{array}{c}2.422^{*} \\
(1.344)\end{array}$ & $\begin{array}{c}2.377^{*} \\
(1.346)\end{array}$ \\
Constant & $\begin{array}{c}7.318^{* * *} \\
(1.687)\end{array}$ & $\begin{array}{c}7.170^{* * *} \\
(2.080)\end{array}$ & $\begin{array}{c}7.745^{* * *} \\
(1.865)\end{array}$ \\
\hline$R^{2}$ & 0.15 & 0.09 & 0.08 \\
\hline
\end{tabular}


Table 8. Price Impact and Macroeconomic Announcement Characteristics

The table displays results of regressions of the estimated $\beta_{k}$ coefficients of equation 10 on the announcement's intrinsic value, relation to fundamentals, tardiness, revision noise derived from nowcasting GDP, as well as the naïve relation to fundamentals, reporting lag, and the naïve revision noise measure described in equation 14. The data sample is from January 1998 to March 2013 , and each regression is based on 36 observations. White standard errors are used, and ${ }^{* * *}$, **, and ${ }^{*}$ represent a 1,5 , and $10 \%$ level of significance, respectively.

2-Year Bond Future

\begin{tabular}{l|cccc|ccc}
\hline & \multicolumn{4}{c}{ Nowcast Measures of } & \multicolumn{3}{c}{ Simpler Measures of } \\
\hline \multirow{4}{*}{$X$} & $\begin{array}{c}\text { Intrinsic } \\
\text { Value } \\
\text { Coefficient }\end{array}$ & $\begin{array}{c}\text { Relation to } \\
\text { Fundamentals }\end{array}$ & $\begin{array}{c}\text { Tardiness } \\
(1)\end{array}$ & $\begin{array}{c}\text { Revision } \\
\text { Noise } \\
(2)\end{array}$ & $\begin{array}{c}\text { Relation to } \\
\text { Fundamentals } \\
(5)\end{array}$ & $\begin{array}{c}\text { Reporting } \\
\text { Lag } \\
(6)\end{array}$ & $\begin{array}{c}\text { Revision } \\
\text { Noise } \\
(7)\end{array}$ \\
& $(0.314)$ & 0.537 & $-0.899^{* * *}$ & -0.308 & $2.605^{*}$ & $-0.619^{*}$ & $0.668^{*}$ \\
Constant & $1.293^{* * *}$ & $(0.335)$ & $(0.311)$ & $(0.343)$ & $(1.295)$ & $(0.324)$ & $(0.337)$ \\
& $(0.409)$ & $(0.595)$ & $(0.566)$ & $(0.347)$ & $(0.613)$ & $(0.435)$ & $(1.180)$ \\
\hline$R^{2}$ & 0.18 & 0.07 & 0.20 & 0.02 & 0.11 & 0.10 & 0.11 \\
\hline
\end{tabular}

5-Year Bond Future

\begin{tabular}{|c|c|c|c|c|c|c|c|}
\hline \multirow[b]{2}{*}{$X$} & \multicolumn{4}{|c|}{ Nowcast Measures of } & \multicolumn{3}{|c|}{ Simpler Measures of } \\
\hline & $\begin{array}{l}\text { Intrinsic } \\
\text { Value } \\
(1)\end{array}$ & $\begin{array}{l}\text { Relation to } \\
\text { Fundamentals } \\
\text { (2) }\end{array}$ & $\begin{array}{c}\text { Tardiness } \\
(3)\end{array}$ & $\begin{array}{c}\text { Revision } \\
\text { Noise } \\
(4)\end{array}$ & $\begin{array}{c}\text { Relation to } \\
\text { Fundamentals } \\
\text { (5) }\end{array}$ & $\begin{array}{c}\text { Reporting } \\
\text { Lag } \\
(6)\end{array}$ & $\begin{array}{c}\text { Revision } \\
\text { Noise } \\
(7)\end{array}$ \\
\hline Coefficient & $\begin{array}{c}2.016^{* * *} \\
(0.648)\end{array}$ & $\begin{array}{l}1.171 \\
(0.707)\end{array}$ & $\begin{array}{c}-2.090 * * * \\
(0.641)\end{array}$ & $\begin{array}{l}-0.434 \\
(0.731)\end{array}$ & $\begin{array}{c}4.559 \\
(2.793)\end{array}$ & $\begin{array}{c}-1.388^{* *} \\
(0.681)\end{array}$ & $\begin{array}{c}1.509^{* *} \\
(0.707)\end{array}$ \\
\hline Constant & $\begin{array}{c}2.935^{* * * *} \\
(0.845)\end{array}$ & $\begin{array}{c}2.923^{* *} \\
(1.256)\end{array}$ & $\begin{array}{c}7.849^{* * * *} \\
(1.166)\end{array}$ & $\begin{array}{c}4.755^{* * *} \\
(0.740)\end{array}$ & $\begin{array}{c}2.820^{* *} \\
(1.322)\end{array}$ & $\begin{array}{c}5.889^{* * * *} \\
(0.914)\end{array}$ & $\begin{array}{l}-0.451 \\
(2.474)\end{array}$ \\
\hline$R^{2}$ & 0.22 & 0.08 & 0.24 & 0.01 & 0.07 & 0.11 & 0.12 \\
\hline
\end{tabular}

\section{0-Year Bond Future}

\begin{tabular}{|c|c|c|c|c|c|c|c|}
\hline \multirow[b]{2}{*}{$X$} & \multicolumn{4}{|c|}{ Nowcast } & \multicolumn{3}{|c|}{ Simpler Measures of } \\
\hline & $\begin{array}{l}\text { Intrinsic } \\
\text { Value } \\
(1)\end{array}$ & $\begin{array}{l}\text { Relation to } \\
\text { Fundamentals } \\
\text { (2) }\end{array}$ & $\begin{array}{c}\text { Tardiness } \\
\quad(3)\end{array}$ & $\begin{array}{l}\text { Revision } \\
\text { Noise } \\
(4)\end{array}$ & $\begin{array}{l}\text { Relation to } \\
\text { Fundamentals } \\
\text { (5) }\end{array}$ & $\begin{array}{l}\text { Reporting } \\
\text { Lag } \\
(6)\end{array}$ & $\begin{array}{c}\text { Revision } \\
\text { Noise } \\
(7)\end{array}$ \\
\hline Coefficient & $\begin{array}{c}2.735^{* * *} \\
(0.882)\end{array}$ & $\begin{array}{c}1.647^{*} \\
(0.959)\end{array}$ & $\begin{array}{c}-2.817^{* * *} \\
(0.875)\end{array}$ & $\begin{array}{l}-0.265 \\
(0.998)\end{array}$ & $\begin{array}{c}5.725 \\
(3.821)\end{array}$ & $\begin{array}{c}-1.779^{*} \\
(0.933)\end{array}$ & $\begin{array}{l}1.870^{*} \\
(0.972)\end{array}$ \\
\hline Constant & $\begin{array}{c}4.224^{* * *} \\
(1.150)\end{array}$ & $\begin{array}{l}4.120^{* *} \\
(1.704)\end{array}$ & $\begin{array}{c}10.86^{* * *} \\
(1.591)\end{array}$ & $\begin{array}{c}6.617^{* * *} \\
(1.011)\end{array}$ & $\begin{array}{l}4.253^{* *} \\
(1.809)\end{array}$ & $\begin{array}{c}8.140^{* * *} \\
(1.252)\end{array}$ & $\begin{array}{c}0.208 \\
(3.402)\end{array}$ \\
\hline$R^{2}$ & 0.22 & 0.08 & 0.23 & 0.00 & 0.06 & 0.10 & 0.10 \\
\hline
\end{tabular}

30-Year Bond Future

\begin{tabular}{|c|c|c|c|c|c|c|c|}
\hline \multirow[b]{2}{*}{$X$} & \multicolumn{4}{|c|}{ Nowcast } & \multicolumn{3}{|c|}{ Naïve } \\
\hline & $\begin{array}{l}\text { Intrinsic } \\
\text { Value } \\
(1)\end{array}$ & $\begin{array}{l}\text { Relation to } \\
\text { Fundamentals } \\
\text { (2) }\end{array}$ & $\begin{array}{c}\text { Tardiness } \\
\text { (3) }\end{array}$ & $\begin{array}{l}\text { Revision } \\
\text { Noise } \\
(4)\end{array}$ & $\begin{array}{l}\text { Relation to } \\
\text { Fundamentals } \\
\quad(5)\end{array}$ & $\begin{array}{l}\text { Reporting } \\
\text { Lag } \\
(6)\end{array}$ & $\begin{array}{c}\text { Revision } \\
\text { Noise } \\
(7)\end{array}$ \\
\hline Coefficient & $\begin{array}{c}3.215^{* *} \\
(1.294)\end{array}$ & $\begin{array}{c}1.764 \\
(1.374)\end{array}$ & $\begin{array}{c}-3.507^{* * *} \\
(1.271)\end{array}$ & $\begin{array}{c}-0.0289 \\
(1.407)\end{array}$ & $\begin{array}{c}6.476 \\
(5.441)\end{array}$ & $\begin{array}{l}-2.191 \\
(1.329)\end{array}$ & $\begin{array}{c}2.113 \\
(1.395)\end{array}$ \\
\hline Constant & $\begin{array}{c}7.318^{* * *} \\
(1.687)\end{array}$ & $\begin{array}{c}7.451^{* * * *} \\
(2.441)\end{array}$ & $\begin{array}{c}15.42^{* * *} \\
(2.313)\end{array}$ & $\begin{array}{c}10.07^{* * *} \\
(1.425)\end{array}$ & $\begin{array}{c}7.455^{* * *} \\
(2.576)\end{array}$ & $\begin{array}{c}12.01^{* * *} \\
(1.784)\end{array}$ & $\begin{array}{c}2.872 \\
(4.884)\end{array}$ \\
\hline$R^{2}$ & 0.15 & 0.05 & 0.18 & 0.00 & 0.04 & 0.07 & 0.07 \\
\hline
\end{tabular}


Figure 1. Macroeconomic Announcement Calendar

This figure shows the usual calendar timing of U.S. macroeconomic announcements across the month. The reference month is labeled as $p$ with most variables released in the subsequent month and some released up to six weeks later. Each GDP series (advance, preliminary, or final) is released on a quarterly basis. Not represented in the figure is initial jobless claims, which is released weekly on Thursday for the previous week. The University of Michigan releases a final version (not shown) of their consumer confidence index two weeks after their advance one.

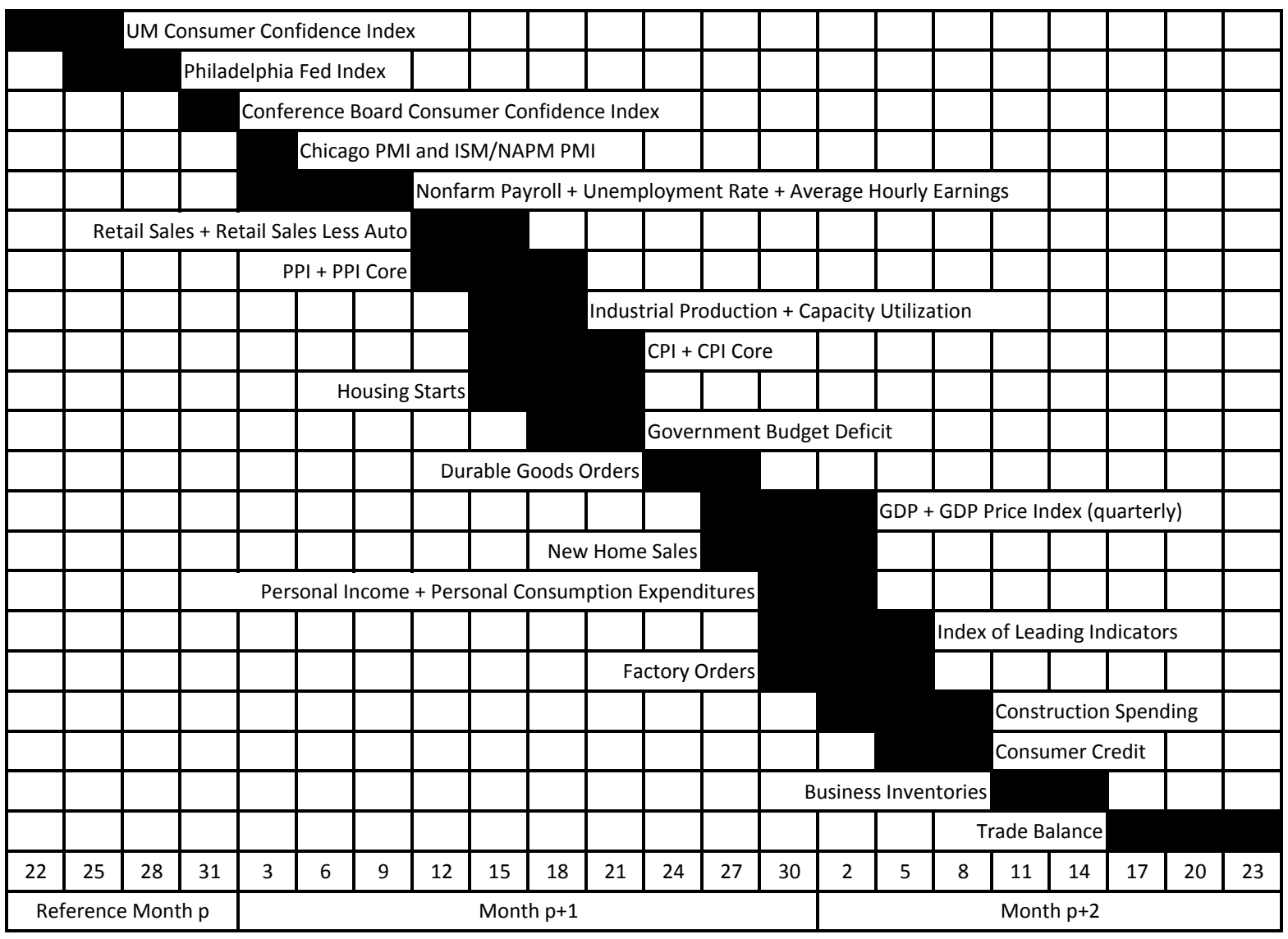




\section{References}

Almeida, Alvaro, Charles Goodhart, and Richard Payne, 1998, The effects of macroeconomic news on high frequency exchange rate behavior, Journal of Financial and Quantitative Analysis 33, 383-408.

Andersen, Torben G., Tim Bollerslev, Francis X. Diebold, and Clara Vega, 2003, Micro effects of macro announcements: Real-time price discovery in foreign exchange, American Economic Review 93, 38-62.

Andersson, Magnus, Jacob W. Ejsing, and Julian von Landesberger, 2008, How do Euro area inflation expectations evolve over time?, European Central Bank.

Andreou, Elena, Eric Ghysels, and Andros Kourtellos, 2010, Regression models with mixed sampling frequencies, Journal of Econometrics 158, 246-261.

Bacchetta, Philippe, and Eric van Wincoop, 2013, On the unstable relationship between exchange rates and macroeconomic fundamentals, Journal of International Economics 91, $18-26$.

Bai, Jennie, Eric Ghysels, and Jonathan H. Wright, 2013, State space models and MIDAS regressions, Econometric Reviews 32, 779-813.

Balduzzi, Pierluigi, Edwin J. Elton, and T. Clifton Green, 2001, Economic news and bond prices: Evidence from the U.S. treasury market, Journal of Financial and Quantitative Analysis 36, 523-543.

Bartolini, Leonardo, Linda Goldberg, and Adam Sacarny, 2008, How economic news moves markets, Current Issues in Economics and Finance 14.

Beechey, Meredith J., and Jonathan H. Wright, 2009, The high-frequency impact of news on long-term yields and forward rates: Is it real?, Journal of Monetary Economics 56, $535-544$. 
Bekaert, Geert, and Eric Engstrom, 2010, Inflation and the stock market: Understanding the "fed model", Journal of Monetary Economics 57, 278-294.

Bernanke, Ben S., and Kenneth N. Kuttner, 2005, What explains the stock market's reaction to federal reserve policy?, Journal of Finance 60, 1221-1257.

Boyd, John H., Jian Hu, and Ravi Jagannathan, 2005, The stock market's reaction to unemployment news: Why bad news is usually good for stocks, Journal of Finance 60, 649-672.

Croushore, Dean, 2011, Frontiers of real-time data analysis, Journal of Economic Literature $49,72-100$.

Ehrmann, Michael, and Marcel Fratzscher, 2004, Taking stock: Monetary policy transmission to equity markets, Journal of Money, Credit, and Banking 36, 719-737.

Ehrmann, Michael, and Marcel Fratzscher, 2005, Exchange rates and fundamentals: New evidence from real-time data, Journal of International Money and Finance 24, 317-341.

Ehrmann, Michael, and David Sondermann, 2012, The news content of macroeconomic announcements - what if central bank communication becomes stale?, International Journal of Central Banking 8, 1-53.

Evans, Martin, 2005, Where are we now? Real-time estimates of the macroeconomy, International Journal of Central Banking 1, 127-175.

Faust, Jon, John H. Rogers, Shing-Yi B. Wang, and Jonathan H. Wright, 2007, The highfrequency response of exchange rates and interest rates to macroeconomics announcements, Journal of Monetary Economics 54, 1051-1068.

Flannery, Mark J., and Aris A. Protopapadakis, 2002, Macroeconomic factors do influence aggregate stock returns, Review of Financial Studies 15, 751-782. 
Fleming, Michael J., and Eli M. Remolona, 1997, What moves the bond market?, Economic Policy Review 3, 31-50.

Fleming, Michael J., and Eli M. Remolona, 1999, Price formation and liquidity in the U.S. treasury market: The response to public information, Journal of Finance 54, 1901-1915.

Giannone, Domenico, Lucrezia Reichlin, and David H. Small, 2008, Nowcasting: The realtime informational content of macroeconomic data, Journal of Monetary Economics 55, $665-676$.

Gilbert, Thomas, 2011, Information aggregation around macroeconomic announcements: Revisions matter, Journal of Financial Economics 101, 114-131.

Goldberg, Linda, and Deborah Leonard, 2003, What moves sovereign bond markets? The effects of economic news on U.S. and German yields, Current Issues in Economics and Finance 9 .

Goldberg, Linda S., and Christian Grisse, 2013, Time variation in asset price responses to macro announcements, Staff Reports 626, Federal Reserve Bank of New York.

Grundy, Bruce D., and Maureen McNichols, 1989, Trade and the revelation of information through prices and direct disclosure, Review of Financial Studies 2, 495-526.

Gürkaynak, Refet S., Brian P. Sack, and Eric T. Swanson, 2005, The excess sensitivity of long-term interest rates to economic news: Evidence and implications for macroeconomic models, American Economic Review 95, 425-436.

Hamilton, James D., and Òscar Jordà, 2002, A model of the federal funds rate target, Journal of Political Economy 110, 1135-1167.

Hautsch, Nikolaus, and Dieter Hess, 2007, Bayesian learning in financial markets: Testing for the relevance of information precision in price discovery, Journal of Financial and Quantitative Analysis 42, 189-208. 
Hess, Dieter, 2004, Determinants of the relative price impact of unanticipated information in U.S. macroeconomic releases, Journal of Futures Markets 24, 609-629.

Hess, Dieter, and Alexandra Niessen, 2010, The early news catches the attention: On the relative price impact of similar economic indicators, Journal of Futures Markets 30, 909937.

Kandel, Eugene, and Neil D. Pearson, 1995, Differential interpretation of public signals and trade in speculative markets, Journal of Political Economy 103, 831-872.

Kim, Oliver, and Robert E. Verrecchia, 1991a, Market reaction to anticipated announcements, Journal of Financial Economics 30, 273-309.

Kim, Oliver, and Robert E. Verrecchia, 1991b, Trading volume and price reactions to public announcements, Journal of Accounting Research 29, 302-321.

Kurov, Alexander, Alessio Sancetta, Georg Strasser, and Marketa Halova Wolfe, 2015, Price drift before U.S. macroeconomic news: Private information about public announcements?, West Virginia University, University of London, Boston College, and Washington State University.

Lapp, John S., and Douglas K. Pearce, 2012, The impact of economic news on expected changes in monetary policy, Journal of Macroeconomics 3, 362-379.

Morris, Stephen, and Hyun Song Shin, 2002, Social value of public information, American Economic Review 92, 1521-1534.

Neely, Christopher J., and S. Rubun Dey, 2010, A survey of announcement effects on foreign exchange returns, Federal Reserve Bank of St. Louis Review 92, 417-463.

Orphanides, Athanasios, 2001, Monetary policy rules based on real-time data, American Economic Review 91, 964-985. 
Rigobon, Roberto, and Brian Sack, 2008, Noisy macroeconomic announcements, monetary policy, and asset prices, in John Y. Campbell, ed., Asset Prices and Monetary Policy, NBER Chapters, chapter 8, 335-370 (NBER).

Veronesi, Pietro, 2000, How does information quality affect stock returns?, Journal of Finance 55, 807-837. 


\section{A Nowcasting Procedure and Data Management}

This appendix provides additional details on the definition of our three nowcasting targets, the nowcasting procedure, and the definition of nowcasting weights in actual and counterfactual settings.

Nowcasting Target and Data Management Our nowcasting target variables are GDP, the GDP price deflator, and the Federal Funds Target Rate (FFTR). We forecast next-quarter GDP (GDP price deflator) once GDP advance has been released, even if same-quarter GDP final is not yet known. We specify the FFTR vector to contain the FFTR on the $15^{\text {th }}$ of each month at 23:59:59. Its change is therefore the difference between its value on the $15^{\text {th }}$ of the current month and its value on the $15^{\text {th }}$ of the previous month.

Mirroring the monthly evolving state of the economy, the data matrix captures the latest known values of each macroeconomic announcement month by month. Figure A1 shows the data structure and its sequential filling.

[Figure A1 about here.]

We consolidate variables that are released piece by piece, namely GDP (advance, preliminary, final), GDP price deflator (advance, preliminary, final), and the University of Michigan (UM) consumer confidence index (preliminary, final). That is, only a single time series of GDP, GDP price deflator, and UM consumer confidence is maintained, and preliminary values are replaced in real time by final ones as they become available. In terms of Figure A1, this means that GDP is only one column, and that earlier values (in boxes marked with "X") are overwritten by later releases. This reduces the 36 announcement series in our sample to 32 consolidated series.

Several of our macroeconomic series refer to periods different from a calendar month. These are variables that are released weekly, quarterly, or irregularly (the FFTR). We convert them to a monthly frequency in the following way: Our only weekly series is initial 
unemployment claims measured in headcounts, which we simply add up. If claims are known for only a part of the month, then we scale them up to the full month, assuming the unknown later part of the month will have same headcounts as its known part. We fill quarterly values into all months of the respective quarter and apply mean-invariant smoothing for compounding growth rates to avoid jumps between quarters.

Our only irregular series is the FFTR and it applies for an unspecified period of time into the future. All other announcements are about the past and are released with delay. We assume that an FOMC announcement pins down the FFTR until the next scheduled FOMC meeting. We allow any FFTR entry to change again if there is another FOMC meeting before the next $15^{\text {th }}$ of a month. If there are several meetings within a month, then only the FFTR of the last meeting before the $15^{\text {th }}$ of each month at 23:59:59 will remain in the data matrix going forward. All other FFTR rates are there only temporarily, and are overwritten by the value announced at that last meeting.

Our sample starts with 33 macroeconomic announcement series for nowcasting in January 1996, which results in 29 series after consolidation. As our sample period expands, more and more macroeconomic variables become available, and starting in February 2002 we use all 36 series. Because principal component analysis does not allow gaps in individual series, the decision on when to include a new series faces a tradeoff: on the one hand, increasing the number of series by including the new series early on and, on the other hand, shortening the length of the effective sample to the length of the shortest (usually the latest starting) series. We base the inclusion decision on the following three principles. First, we exclude at each point in time variables with less than five observations. Second, we exclude a variable if its inclusion would lead to less than three periods with all variables available. Third, we delete additional variables iteratively until the number of periods with all variables available is as least as large as the number of variables used. Because the number of available reference periods $p$ is small in the first two years (1996 and 1997), we include (for small $t$ ) a series only if less than half of its observations are missing. 
Nowcasting Setup and Procedure We use a 5-dimensional state vector, consisting of two global factors, one real factor, one nominal factor, and one forward-looking factor. The global factors are based on all 36 announcements plus the FFTR. The real factor is based on 21 announcements: unemployment rate, durable goods orders, housing starts, trade balance, nonfarm payroll, advance retail sales, capacity utilization, industrial production, business inventories, construction spending, factory orders, new home sales, personal consumption, personal income, monthly budget statement, consumer credit, initial jobless claims, GDP advance, preliminary and final, and retail sales less autos. The nominal factor is based on eight announcements: Consumer Price Index, Producer Price Index, CPI ex food and energy, PPI ex food and energy, average hourly earnings, GDP price deflator advance, preliminary and final. The forward-looking factor is based on ten announcements: index of leading indicators, consumer confidence index, ISM PMI, Chicago PMI, Philadelphia Fed index, UM consumer confidence preliminary and final, durable goods orders, housing starts, and factory orders.

Our setup assumes two common shocks and an autoregressive order of the state vector $F$ of 1 . For each forecasting target and each information set $t$, the Kalman filter produces a Kalman gain matrix for each reference month $p$. In a balanced sample, the Kalman gain of interest would obviously be the gain in the very last period. Standard results show that the Kalman gain converges to a constant matrix as $p$ becomes large. In our case, the most recent period with all announcements is usually two months earlier, and more recent months contain only a subset of the announcements in varying compositions. The convergence result for Kalman gains does therefore not apply for this most recent period.

In our setup with unbalanced data, the last converged Kalman gain (from the very last period before some announcements are missing) reflects the past. It is an ex-post measure of what the gain used to be. Instead, we use the Kalman gain in the most recent month for which the respective variable has data. Because the time series of each announcement ends at a different time, each variable has an individually different period for Kalman gain 
calculation. Both Kalman gain vectors would be identical if a given variable was always announced last.

Nowcasting Regressions and Weights We refine the in-sample estimates of the latent factors by Kalman smoothing, which improves estimates of past factors by updating them based on subsequently (but not after time $T$ ) revealed information.

Using the estimates of $B_{T}$ and $C_{T}$, we can forecast the factors (or states) out-of-sample for $t>T$. We regress the in-sample announcements of GDP, the GDP price deflator and the FFTR available at time $T$ on the factor estimates at time $T$; that is,

$$
A_{\bar{p}, T}^{k}=\alpha_{T}+\beta_{T} \tilde{\Phi}_{\bar{p}, T}
$$

where $\bar{p}$ indices the reference periods of $A^{k}$ and is restricted to the periods for which the values of $A_{\bar{p}, T}^{k}$ and $\tilde{\Phi}_{\bar{p}, T}$ are known at time $T$. For the quarterly variables GDP and the GDP price deflator, $\bar{p}$ denotes quarters; for the FFTR, it denotes months. Accordingly, the independent variable $\tilde{\Phi}_{\bar{p}, t}=\left[\tilde{\Phi}_{\bar{p}, t}^{G 1}, \tilde{\Phi}_{\bar{p}, t}^{G 2}, \tilde{\Phi}_{\bar{p}, t}^{R}, \tilde{\Phi}_{\bar{p}, t}^{N}, \tilde{\Phi}_{\bar{p}, t}^{F}\right]$ contains the arithmetic average of each estimated factor $\tilde{\Phi}_{p, t}^{i}$ during period $\bar{p}$. The out-of-sample nowcast for announcement $A_{p, t}^{k}$ to be released at time $t>T$ based on information until time $T$ is then

$$
\hat{A}_{\bar{p}, T}^{k}=\hat{\alpha}_{t}+\hat{\beta}_{T} \tilde{\Phi}_{\bar{p}, T}^{f}
$$

where $\tilde{\Phi}_{\bar{p}, T}^{f}$ is the average Kalman smoother forecast for period $\bar{p}$ based on information until time $T$.

To account for the discreteness of the FFTR, we round FFTR changes to $0.25 \%$ and define as many ordered probit categories as needed at any given time $t$. We then forecast the FFTR by ordered probit following Hamilton and Jordà (2002).

Repeating this procedure for each announcement time in our sample gives us a sequence of coefficient vectors $\hat{\beta}_{t}$ and of nowcasts $\hat{A}_{p(t), t}^{k}$, where $p(t)$ is the reference period of the very 
next announcement of variable $k$ after time $t$.

The root mean squared forecasting error (RMSFE) of our nowcast of GDP is 1.73 during the period from 1996 to 2012, much lower than that of a random walk forecast of 2.18. The RMSFE for the GDP price deflator is 0.86 , which is also lower than that of a random walk forecast with 1.29. For FFTR, the RMSFE is 0.19, which is also better than a random walk with 0.25 . Nevertheless, obtaining an optimal nowcast is not a goal of this paper. It is for us just a means to evaluate the impact of announcement characteristics consistently.

We assume that agents with rational expectations care about the best case scenario, i.e., the intrinsic value when the announcement is just released. We calculate these (ex-post) weights on the standardized, transformed macroeconomic variables at announcement time. That is, we multiply, separately for each announcement, the vector of coefficients $\hat{\beta}_{t}$ with the Kalman gain vector of the period of interest. We use the absolute value of these weights in subsequent analysis to capture the direction-free impact of an announcement.

Counterfactual Announcement Time and Revision Status In order to measure the impact of an announcement while controlling for timing and noise, we create counterfactual datasets. These datasets differ from the original dataset in the release timing, the revision status, or both. We modify the respective property of only one macro announcement series per nowcasting exercise.

To control for release timing, we counterfactually reorder the data. To do so, we identify the earliest announcement for each reference period and set the counterfactual announcement time of variable of interest to one second before this previously earliest announcement.

To control for revision status, we counterfactually replace all releases of the variable of interest by final revision values. Where final values are unavailable, we keep the value of the initial release. 


\section{B Macroeconomic Variable Transformations}

We transform the macroeconomic series, i.e., the dependent variable in the observation equation (13), in order to approximate a linear relationship with the forecasting object.

Table B1 summarizes the transformations.

[Table B1 about here.] 


\section{Table B1. Transformations of Macroeconomic Announcements}

This table reports, for each of the 36 announcements, the original unit used in both original agency reports and Bloomberg expectations, and the transformation used in this paper.

\begin{tabular}{|c|c|c|c|}
\hline$k$ & Announcement & Original Unit & Transformation \\
\hline & Real Activity & & \\
\hline 1 & GDP advance & $\%$ change & Original \\
\hline 2 & GDP preliminary & $\%$ change & Original \\
\hline \multirow[t]{2}{*}{3} & GDP final & $\%$ change & Original \\
\hline & Prices & & \\
\hline 4 & GDP price deflator advance & $\%$ change & Original \\
\hline 5 & GDP price deflator preliminary & $\%$ change & Original \\
\hline \multirow[t]{2}{*}{6} & GDP price deflator final & $\%$ change & Original \\
\hline & Real Activity & & \\
\hline 7 & Unemployment report & $\%$ & Original \\
\hline 8 & Nonfarm payroll employment & change & Original/ NFP Population \\
\hline 9 & Retail sales & $\%$ change & Original \\
\hline 10 & Retail sales less automobiles & $\%$ change & Original \\
\hline 11 & Industrial production & $\%$ change & Original \\
\hline 12 & Capacity utilization & $\%$ & Original \\
\hline 13 & Personal income & $\%$ change & Original \\
\hline \multirow[t]{2}{*}{14} & Consumer credit & change & $\%$ change \\
\hline & Consumption & & \\
\hline 15 & Personal consumption expenditures & $\%$ change & Original \\
\hline \multirow[t]{2}{*}{16} & New home sales & level & $\%$ change \\
\hline & Investment & & \\
\hline 17 & Durable goods orders & $\%$ change & Original \\
\hline 18 & Construction spending & $\%$ change & Original \\
\hline 19 & Factory orders & $\%$ change & Original \\
\hline \multirow[t]{2}{*}{20} & Business inventories & $\%$ change & Original \\
\hline & Government Purchases & & \\
\hline \multirow[t]{2}{*}{21} & Government budget deficit & level & $\%$ change \\
\hline & Net Exports & & \\
\hline \multirow[t]{2}{*}{22} & Trade balance & level & $\%$ change \\
\hline & Prices & & \\
\hline 23 & Average hourly earnings & $\%$ change & Original \\
\hline 24 & Producer price index & $\%$ change & Original \\
\hline 25 & Core producer price index & $\%$ change & Original \\
\hline 26 & Consumer price index & $\%$ change & Original \\
\hline \multirow[t]{2}{*}{27} & Core consumer price index & $\%$ change & Original \\
\hline & Forward Looking & & \\
\hline 28 & UM consumer confidence preliminary & index & Original \\
\hline 29 & Philadelphia Fed index & index & Original \\
\hline 30 & UM consumer confidence final & index & Original \\
\hline 31 & $\mathrm{CB}$ consumer confidence index & index & Original \\
\hline 32 & Chicago PMI & index & Original \\
\hline 33 & ISM PMI & index & Original \\
\hline 34 & Housing starts & level & $\%$ change \\
\hline 35 & Index of leading indicators & $\%$ change & Original \\
\hline 36 & Initial unemployment claims & level & Original/ NFP Population \\
\hline
\end{tabular}


Figure A1. Data Structure Underlying Nowcasting

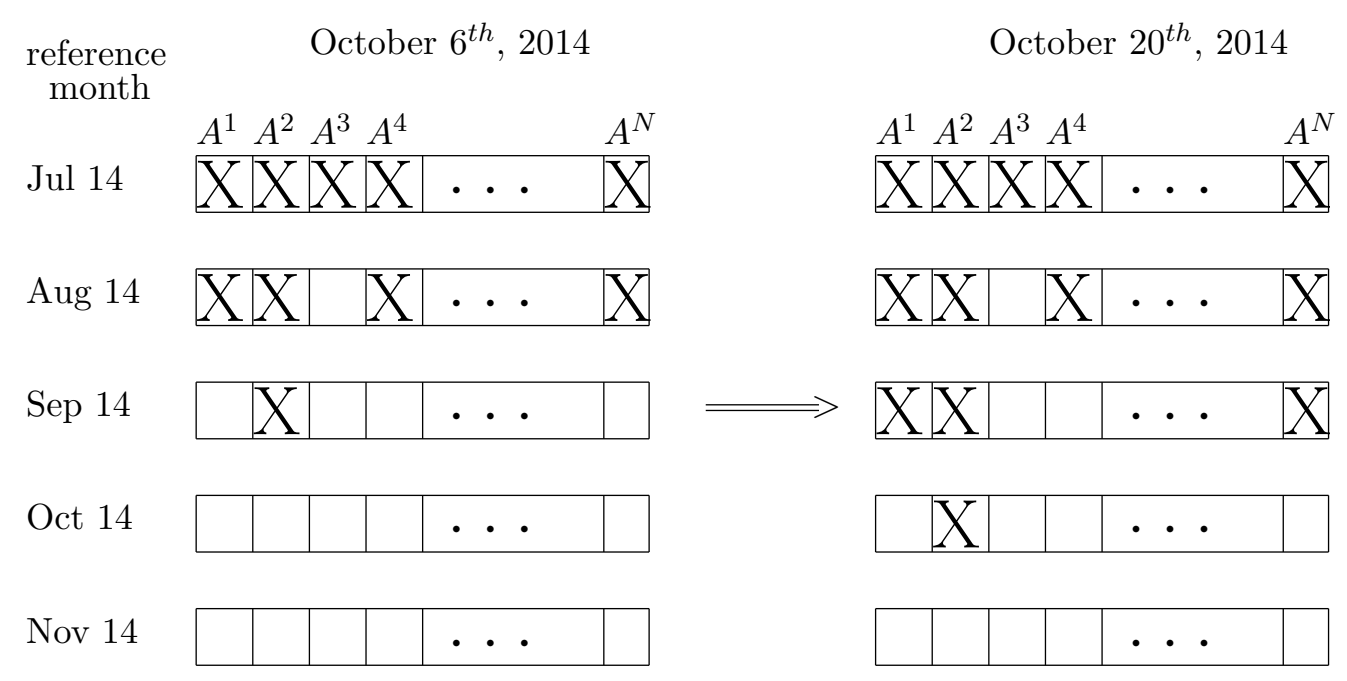

